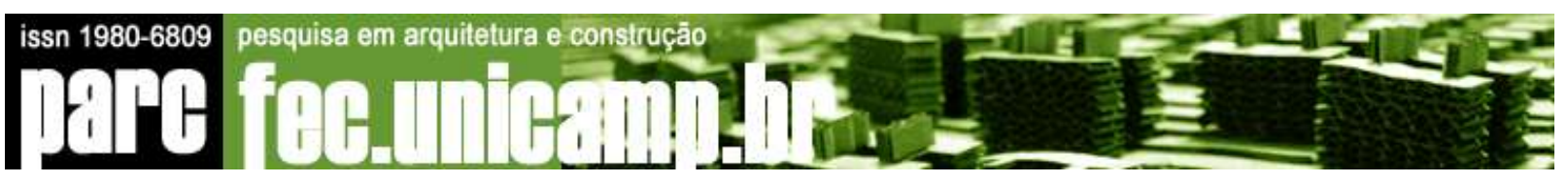

\title{
Para Um Método de Análise Espaço-Uso - uma abordagem sintáctica
}

Towards a Space-Use Analysis Method - a syntactic approach

\begin{abstract}
ANA TOMÉ 1
TERESA HEITOR ${ }^{2}$

${ }^{1}$ Arquitecta, Graduada pela Faculdade de Arquitectura, Universidade Técnica de Lisboa (UTL), Mestre em Construção pelo Instituto Superior Técnico da Universidade Técnica de Lisboa (IST-UTL), Doutor em Arquitectura pelo IST-UTL, Professora Auxiliar no IST-UTL, Investigadora do Núcleo 8 Arquitectura do Instituto de Engenharia de Estruturas, Território e Construção (ICIST).

${ }^{2}$ Arquitecta, Graduada pela Escola de Belas Artes de Lisboa, Mestre em Desenho Urbano pela Oxford Brooks University, Reino Unido, Doutor em Engenharia do Território pelo Instituto Superior Técnico da Universidade Técnica de Lisboa (IST-UTL), Agregada em Arquitectura pelo IST-UTL, Professora Catedrática no IST-UTL, Investigadora do Núcleo 8 Arquitectura do Instituto de Engenharia de Estruturas, Território e Construção (ICIST).

\footnotetext{
1 anatome@civil.ist.utl.pt

${ }^{2}$ teresa@civil.ist.utl.pt
}

\section{Resumo}

Os artefactos arquitectónicos não são apenas objectos físicos, mas objectos sociais que estruturam relações de co-presença e de encontro pelo modo como suportam a distribuição dos fluxos de movimento e, consequentemente, organizam os usos que neles se realizam.

Partindo de tal pressuposto e considerando a necessidade de aprofundar a compreensão das relações espaço-uso, neste trabalho desenvolveram-se procedimentos analíticos orientados para o estudo das condições de uso dos artefactos arquitectónicos e, subsequentemente, para um melhor entendimento dos nexos estabelecidos com a condição espacial. Pretendeu-se deste modo contribuir para 0 desenvolvimento de técnicas baseadas numa visão computacional da mobilidade e interacção dos utilizadores produzindo registos documentais não arbitrários dos seus padrões de movimento/navegação e de ocupação/co-presença e fundamentando a sua análise em termos quantitativos.

A tecnologia vídeo permitiu o registo simultâneo do movimento e do espaço que o conforma. A visão computacional da mobilidade em espaços informais de aprendizagem (átrios) permitiu obter e tratar dados em quantidade, condição necessária à fundamentação da relação espaço-uso. O método 


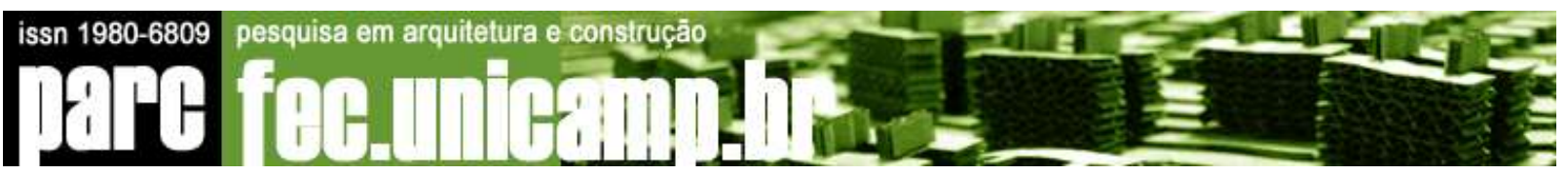

seguido considerou a instalação de um sistema de aquisição de imagens analisáveis por um algoritmo de detecção e seguimento automático de utilizadores para efeitos de processamento da informação.

Os padrões de movimento/navegação e de ocupação/co-presença obtidos foram correlacionados com as propriedades configuracionais obtidas pela aplicação do modelo descritivo da Sintaxe Espacial (Hillier e Hanson, 1984). Foi possível analisar nexos entre a configuração do espaço e os padrões de movimento/navegação e de ocupação/co-presença, questão fulcral para o processo conceptual em Arquitectura.

Palavras-chave: Análise espaço-uso; Visão computacional; Padrões de movimento/navegação e padrões de ocupação/co-presença; Índices de ocupação/movimento; Sintaxe Espacial.

\section{Abstract}

Architectural artefacts are not just physical entities, but social entities that structure relationships of copresence and encounter among their users by distributing the movement flows and, consequently, organizing uses.

Based on this assumption and considering the need to deepen the understanding of the space-use relationships, this paper is focused on analytical procedures aiming at the study of the functional condition of architectural artefacts and, subsequently, promoting a better understanding of the connections established with the spatial condition. The goal is to contribute to the development of techniques based in a computer vision of the mobility and users interaction producing non-arbitrary registries of their movement/navigation and occupancy/co-presence patterns and basing its analysis in quantitative terms.

Video technology allowed the simultaneous register of movement and space. The computer vision of the mobility in informal learning spaces (atriums) allowed to gathering the amount of data necessary to carry out the space-use analysis. The proposed method implied the installation of an image acquisition system suitable as an input to an algorithm of automatic user detection and tracking.

Movement/navigation and occupancy/co-presence patterns were correlated with configurational properties obtained by applying Space Syntax descriptive model (Hillier e Hanson, 1984). It was possible to analyze relations between the spatial configuration and the movement/navigation and occupancy/co-presence patterns, a key-question within the architectural conceptual process.

Keywords: Space-use analysis method; Computer vision; Movement/navigation patterns and occupation/co-presence patterns; Occupation/movement indices; Space Syntax. 


\title{
Para Um Método de Análise Espaço-Uso - uma abordagem sintáctica
}

\section{INTRODUÇÃO}

\author{
"Medir tudo o que seja mensurável. \\ Tornar mensurável o que não se pode medir." \\ Galileo Galilei
}

No âmbito dos estudos espaço-funcionais, entendido como campo de investigação na área disciplinar da arquitectura, a Sintaxe Espacial constitui um modelo de análise centrado na descrição do espaço e das suas capacidades funcionais desenvolvido na Bartlett School, a partir do final da década de 70, sob a orientação de Bill Hillier e de Julienne Hanson (Hillier e Hanson, 1984). Avaliada na vertente teórica a Sintaxe Espacial representa um ponto de viragem num conjunto de pressupostos indispensáveis à investigação e demonstração da realidade espaço-funcional. A relevância analítica do modelo sintático assenta numa lógica social do espaço: modo como num determinado sistema e segundo uma lógica binária, as conexões entre espaços existem ou não, permitindo ou não, a ocorrência de relações de copresença e de encontro entre utilizadores. Dessa lógica social são deduzidas as formulações da Sintaxe Espacial metodicamente organizadas segundo representações descritivas e simplificadas dos sistemas espaciais as quais pretendem constituir-se como ferramentas analíticas dos factos concretos e contingentes das relações entre o espaço construído e o seu uso. No entanto, por serem contingentes tais factos só podem ser conhecidos pela observação. Do estudo dos factos será dedutível o conhecimento dos condicionalismos que os determinaram e será possível averiguar se tais condicionalismos são regidos por leis.

A problemática da observação tem sido a vexata quaestio que perturba o quadro teórico-metodológico da Sintaxe Espacial. Os métodos de observação praticados são inesperadamente elementares e surpreendentemente alheios às tecnologias contemporâneas. Recorrem, quase exclusivamente, a "observadores em campo", colaboradores nos quais se presumem qualidades intelectuais e físicas indispensáveis à prática dos actos de observação e o mérito de terem capacidade para registar graficamente os padrões de navegação ocorridos nos espaços examinados e, ainda, a generosa disponibilidade para se posicionarem, a qualquer momento, em qualquer contexto espacial. 


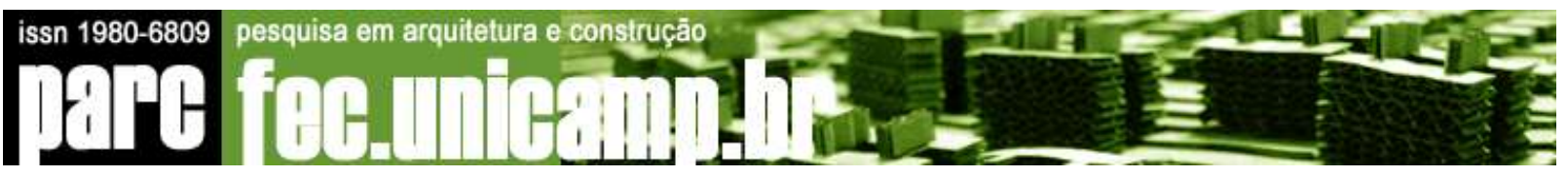

Da informação conhecida não consta que tais colaboradores sejam profissionalizados o que permite admitir, por um lado a improbabilidade de uma tal conjunção de competências e boas vontades e, por outro lado, a incidência de componentes subjectivas na interpretação dos factos observados. Escreveu Lahr (1948, p. 373) que a observação deve ser exacta e completa "deve perceber tudo o que há, nada mais do que há, sem nunca misturar com a verificação objectiva dos factos a interpretação mais ou menos subjectiva que lhes podemos dar".

À observação também se deve exigir que seja permanente e sucessiva para que possam ser estudadas todas as fases dos actos observados e a sequência segundo a qual ocorrem. Tais comuns procedimentos dificilmente se reconhecem no Observation Procedures Manual (Vaughan, 2001) produzido no círculo da Space Syntax (UCL Bartlett School of Graduate Studies, Space Research Group, Space Syntax Laboratory).

O recurso à simulação dos fluxos de movimento através dos agentes (Turner e Penn, 2002), peões virtuais informados pela configuração visual do espaço para progredir, de modo estocástico, através dos sistemas espaciais, também não constituirá alternativa credível às deficiências de um manual de observação baseado no factor humano, no papel e no lápis. Tal abordagem encerra o modelo sintáctico em si mesmo autovalidando-se a partir dos seus próprios pressupostos ao invés de, por confronto com o desempenho dos ambientes construídos em uso, se autoquestionar e progredir (FIG. 1). Acresce que, os procedimentos de observação definidos pelo Manual continuam a ser o meio de validar os padrões de navegação dos agentes. Segundo qualquer perspectiva, a observação do movimento será uma questão incontornável no contexto da teoria sintáctica.

Assim, as insuficiências dos métodos de observação consagrados no Observation Procedures Manual, e correntemente praticados no círculo da comunidade sintáctica, não comprometem apenas a validação do modelo sintáctico, levantam também obstáculos ao seu desenvolvimento.

Se o espaço possui uma configuração, i.e., uma forma como as suas partes se relacionam entre si, os fluxos de movimento modelados pela estrutura configuracional do espaço também possuirão uma configuração, i.e., uma forma entendida como a organização 


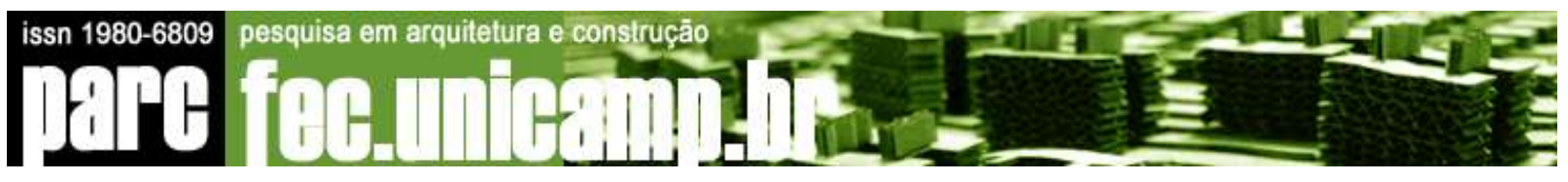

sequenciada dos posicionamentos espaciais. Ambas as configurações - a do espaço e a do movimento - estabelecem, necessariamente, relações entre si na medida em que o primeiro condiciona e o segundo é condicionado. O esclarecimento da natureza dessas relações requer como quesitos prévios a visualização e caracterização objectiva da configuração do movimento (FIG. 2). O Método dos Portões epitetado como o "burro de carga" dos processos de observação (Vaughan, 2001) pela suposta quantidade de dados que permite recolher (por isso mesmo correntemente aplicado) apenas possibilita uma informação intermitente/desconexa sobre essa configuração.

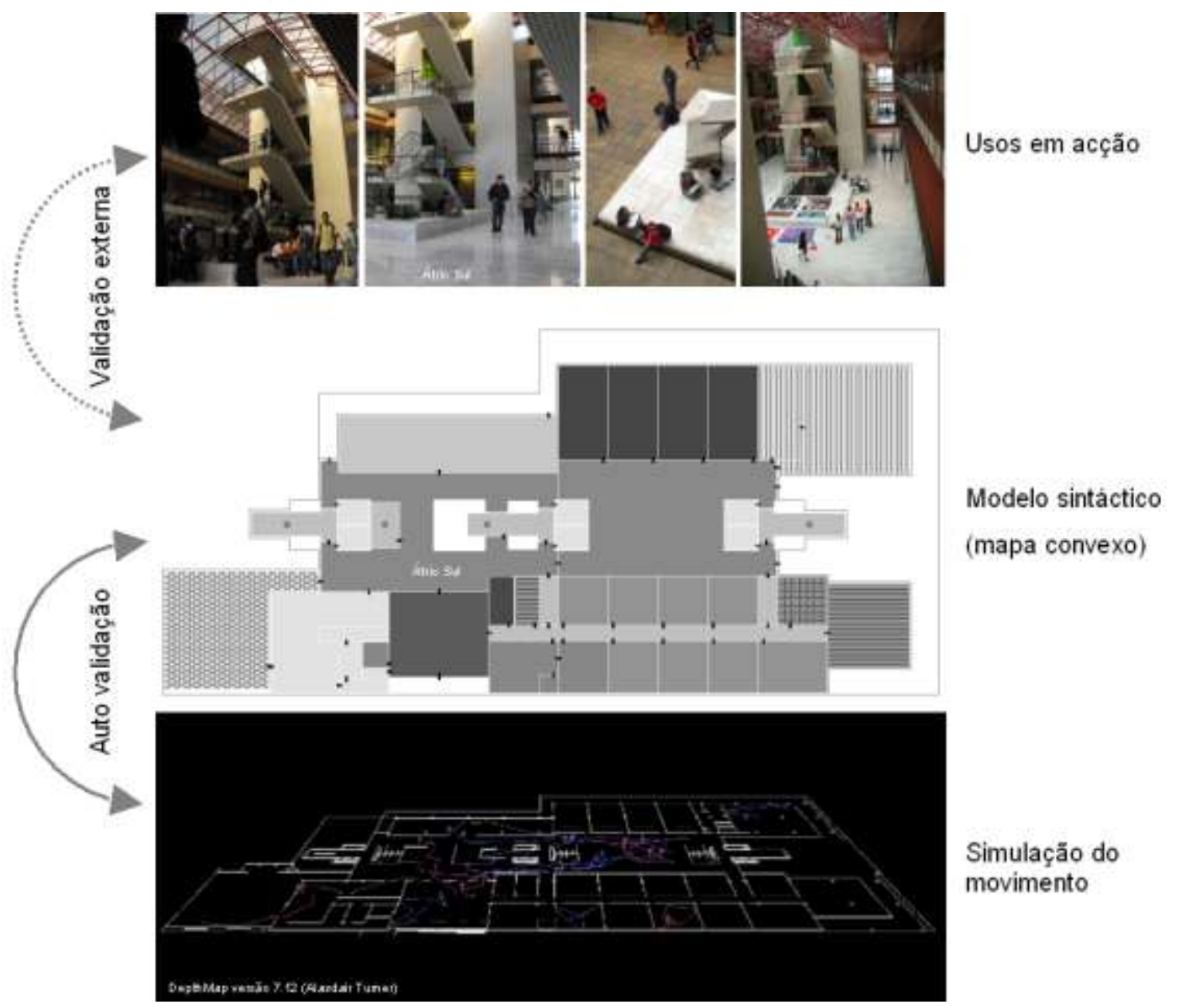

FIGURA 1: Modelo sintáctico: auto-validação baseada na simulação do movimento (agentes libertados num ambiente virtual) versus validação externa baseada na observação do movimento real. DECivil ${ }^{1}$ campus do $\mathrm{IST}^{2}$, Lisboa: usos em acção (Átrio Sul); mapa convexo ${ }^{3}$ (piso térreo). 


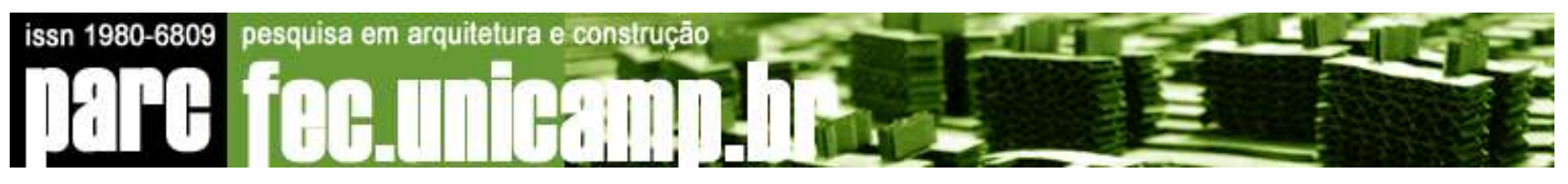

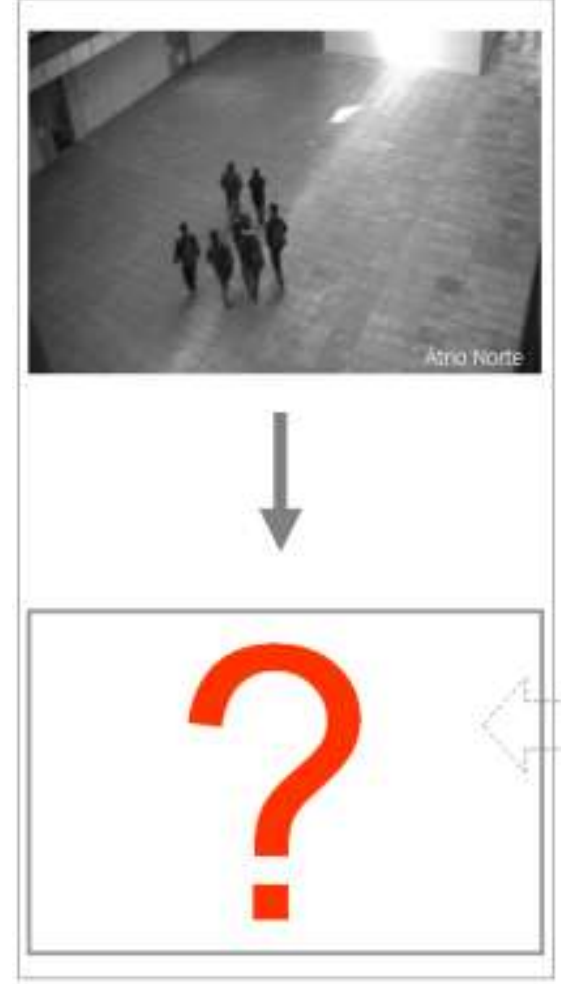

Configuraçăo do movimento

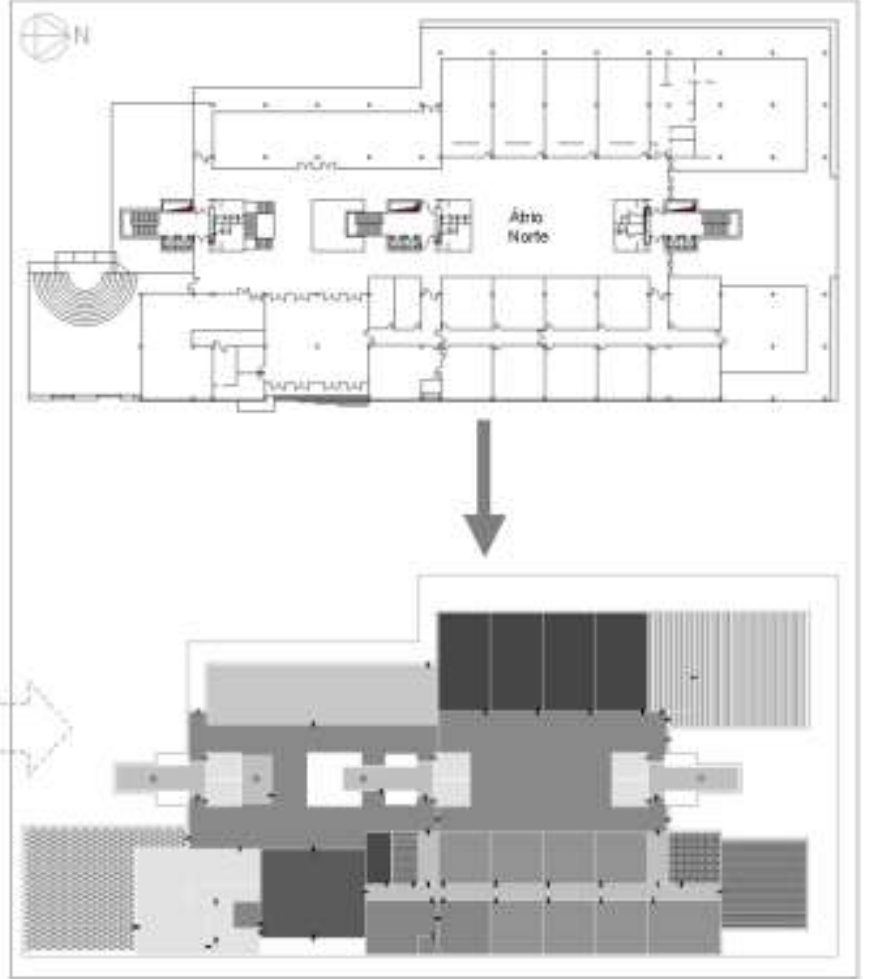

Configuraçăo do espaço

FIGURA 2: Como captar a configuração do movimento?

Configuração do espaço: mapa convexo do DECivil ${ }^{1}$, piso térreo.

A possibilidade de visualizar a configuração do movimento permitiria organizar uma tipificação desses movimentos, atendendo à geometria e densidade das trajectórias registadas, fundamentando-se uma classificação sistemática das configurações da mobilidade (Heitor e Tomé, 2009) ainda não esclarecidas pelos modelos sintácticos descritores dos movimentos espaciais, apenas relacionados com os comportamentos básicos da ocupação e do movimento (Hillier, 1996). A taxonomia das configurações da mobilidade agrega uma outra questão, a de se averiguar se será possível medir, ou conferir alguma mensurabilidade, à configuração dos movimentos, tornando possível fundamentar a ocorrência de regularidades entre espaço e uso, ou seja, medir a relação entre ambos ou, pelo menos, estabelecer correlações não-arbitrárias.

Reconhecida a relevância da Sintaxe Espacial e reconhecendo-se-lhe, também, uma capacidade analítica muito condicionada por insuficientes meios fundamentadores da prática 


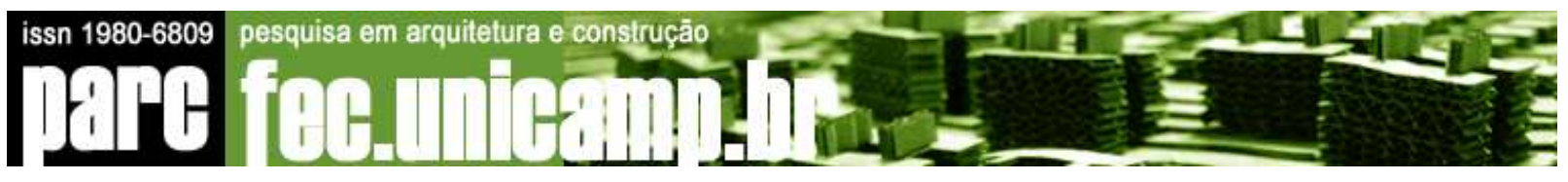

sintáctica, foi delineado o objectivo de dotar o estudo das relações espaço-uso com instrumentação metodicamente aplicável à aquisição de informações sobre o movimento, parcela dessas relações que, na actualidade das tecnologias disponíveis, será a de menor complexidade na representação e na interpretação sendo, no entanto, a de maior interesse para os conceitos da Sintaxe Espacial.

\section{PROCEDIMENTOS METODOLÓGICOS}

Quais os meios técnicos e os métodos que permitem tornar explícita e mensurável a natureza da mobilidade humana?

Para o objectivo pretendido reconheceram-se, nos processos videográficos consideráveis vantagens dado permitirem:

- Registar o movimento no contexto espacial observado, processo não praticável pelos métodos preconizados no Space Syntax Observation Procedures Manual.

- Descrever o movimento ao longo do tempo.

- Observar, sem perturbar, os comportamentos espaciais (observação não intrusiva).

- Gravar em contínuo durante longos períodos.

- Representar a veracidade dos factos observados não sendo susceptíveis de erros ou manipulações.

- Visionar repetidamente os registos, propriedade indispensável à detalhada compreensão dos fenómenos de movimento.

- Quantificar as dinâmicas de mobilidade observadas.

- Partilhar integralmente os dados entre investigadores.

A aquisição de dados exactos é condição essencial na análise das relações espaço-uso e quanto maior for o volume desses dados tanto mais possível será inferir a natureza e o grau de ocorrência dos movimentos observados só assim sendo viável identificar as regularidades, i.e., "os padrões na superfície dos fenómenos" (Hillier, 1996, p.4). Identificadas tais regularidades será possível fundamentar conexões com as propriedades espaciais dos contextos que as suportam. Por outro lado, o continuum da observação permitirá registar os fenómenos de movimento integralmente, factor relevante para o estudo dos comportamentos exploratórios dos utilizadores e contributo importante para uma futura taxonomia do 


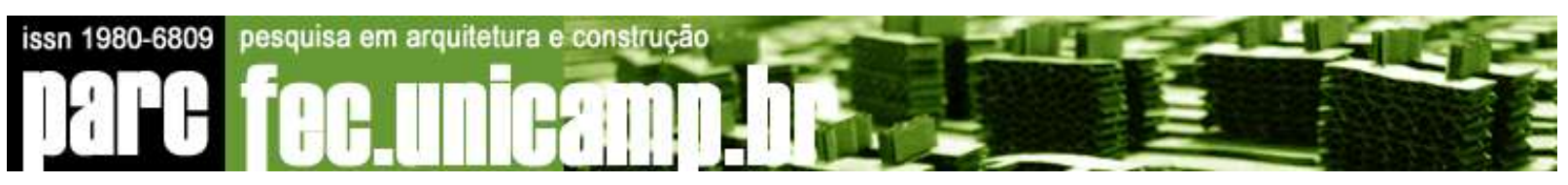

movimento e estudo das interacções utilizador-utilizador e utilizador-espaço contentor. Tais condições implicam o recurso a meios com capacidade de aquisição e processamento dos dados, somente atingíveis por instrumentos técnicos e informáticos de interpretação.

Como contexto de estudo propício foi escolhido o DECivil ${ }^{1}$ situado no campus do $\mathrm{IST}^{2}$, em Lisboa, devido à intensa utilização diária do edifício pela população académica (predominantemente estudantes). A observação das dinâmicas de uso concentrou-se no átrio central desse pavilhão, o núcleo de transição entre o interior e o exterior. Neste espaço convergem diariamente os membros da comunidade académica do IST, alunos, professores e funcionários dos departamentos e serviços aí residentes. Devido à localização das três colunas de acessos verticais, o átrio central subdivide-se por duas zonas distintas: o Átrio Norte e o Átrio Sul. Os dois átrios apresentam dinâmicas de uso muito diferenciadas (FIG. 3).

O Átrio Sul, adjacente ao átrio de entrada e à cafetaria, constitui a plataforma de distribuição dos fluxos internos. O Átrio Norte, adjacente a salas de aula do $\mathrm{MA}^{4}$ e ao refeitório, embora de utilização menos intensa, é um espaço propício a eventos curriculares e extra curriculares, nomeadamente, exposições e outras actividades afins do prolongamento do trabalho lectivo para o exterior das salas de aula ou da sua mostra pública.

O interesse dos átrios decorre do facto dos seus padrões de uso não serem prédeterminados, antes se caracterizarem pela sua variabilidade/mutabilidade, em decorrência do não condicionamento das actividades que lhes estão associadas podendo ser entendidos como espaços dotados de capacidades generativas (Hillier e Penn, 1991) no que concerne à produção de padrões de encontro. 

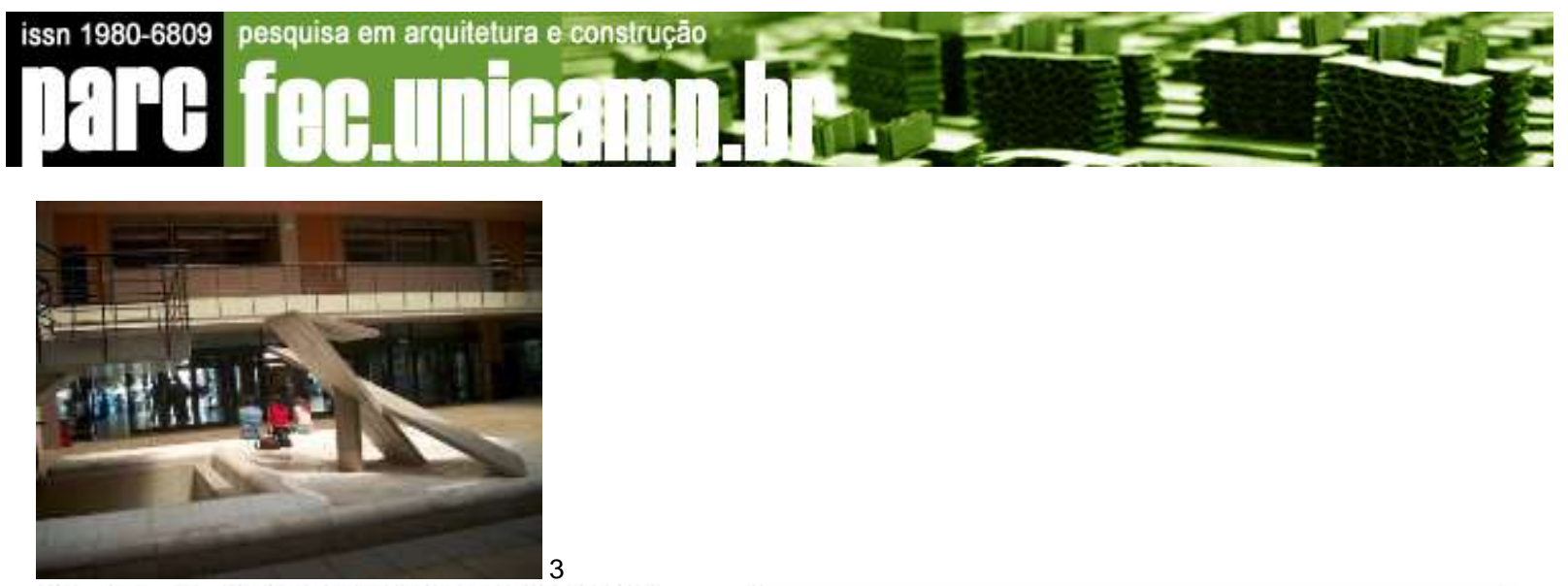

Ext - exterior, AE - Atrio de Entrada; AS - Atria Sul; AN - Atrio Norte; C3 - Corredor 24 horas; B-Bar; Esp - Esplanada; E24 - Espero 24 Horas: NE - Núcleos de Estudantes,Rec; - Recepçé, M- Museu, SA1 - Salas de Arcuitectura do 1tano; SA5 - Salas de Arquitectura do $5^{5}$ Bno; R - Refentónio; Sp - Sala de Apoio.
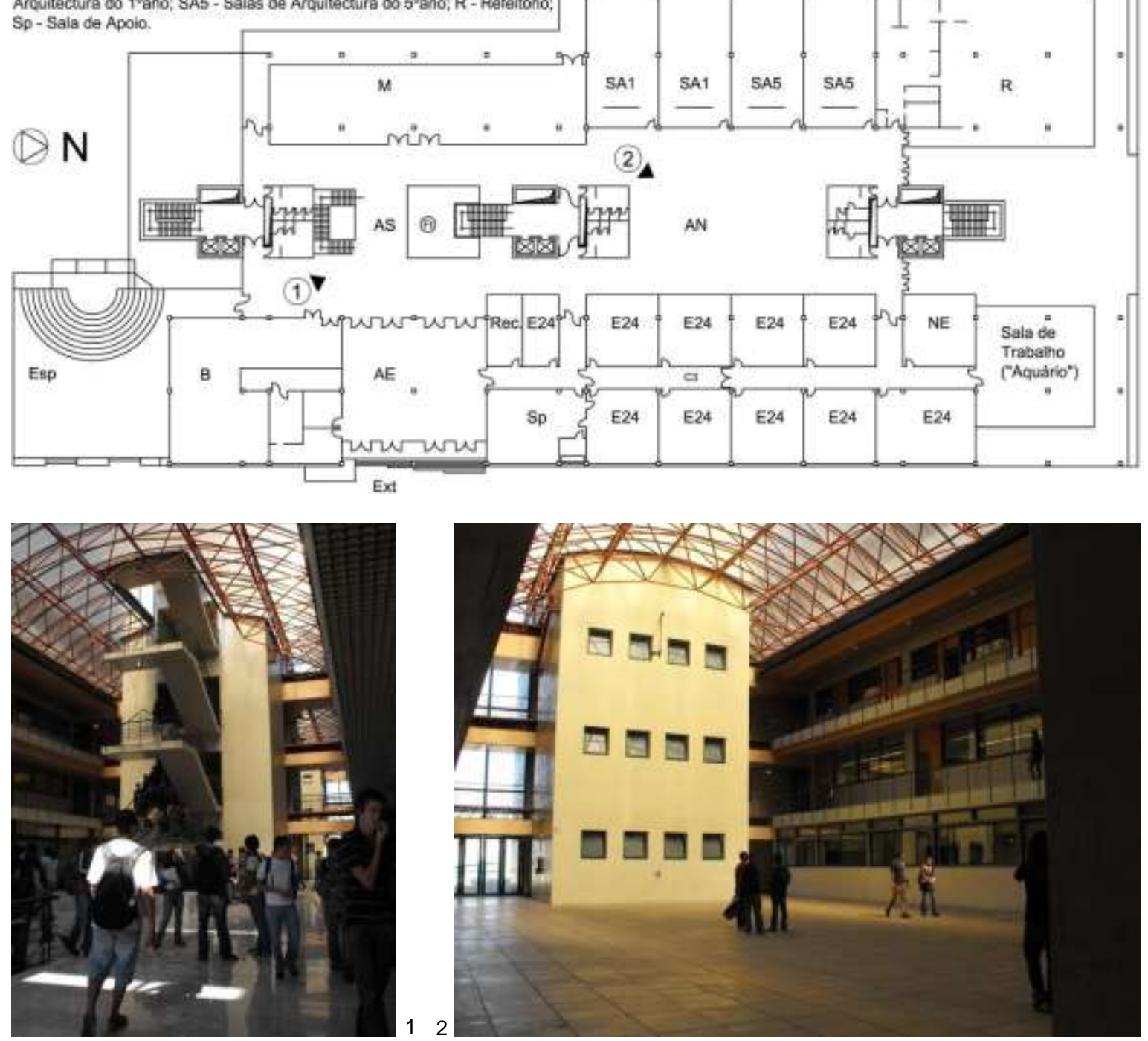

FIGURA 3: DECivil: o átrio central - planta do piso térreo. Átrio Sul (1) e Átrio Norte (2). A planta indica os pontos de vista das imagens. Fonte desactivada (3) no Átrio Sul: relação visual com o átrio de entrada. 


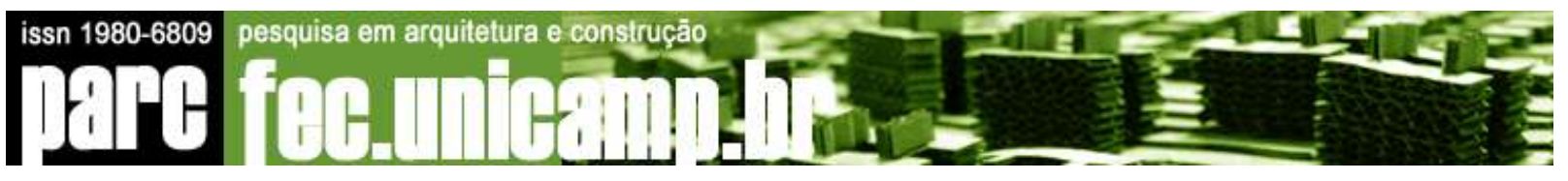

A visão computacional da mobilidade nos Átrios do DECivil exigiu a instalação de um sistema de aquisição contínua de dados de imagem incorporando duas câmaras de vídeo vigilância de alta resolução AV5100 da Arecont Vision (FIG. 4) consideradas necessárias e suficientes. O processamento dos dados resultou da aplicação do ArquiTracking, algoritmo de detecção e seguimento automático desenvolvido pelo INOV ${ }^{5}$ especificamente para o objectivo deste estudo.

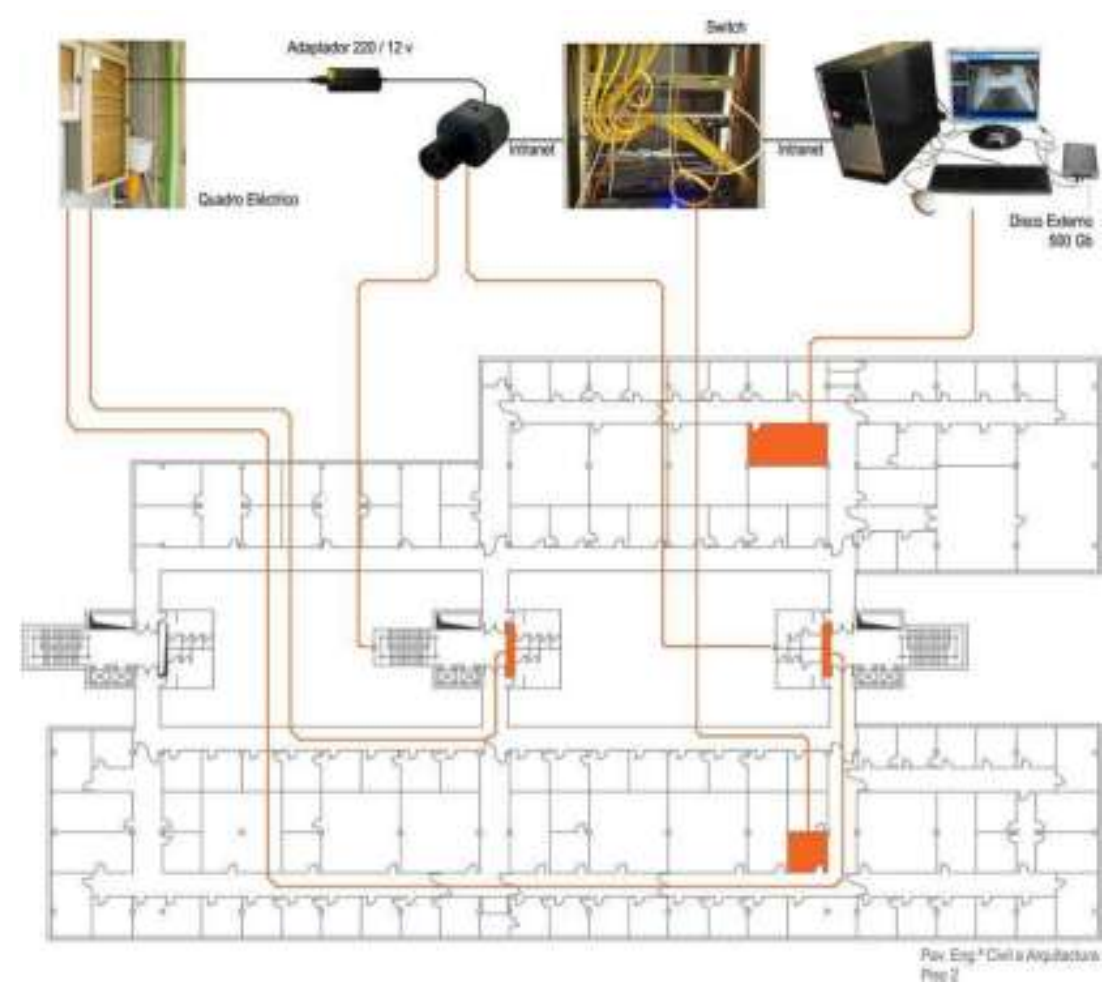

FIGURA 4: Sistema de aquisição de imagens: esquema síntese.

As especificações técnicas das Arecont, equipadas com objectivas F1,8/4-10mm, corresponderam às pré-exigências do tratamento informático: resolução de 5 Megapixéis e frame rate de $9 \mathrm{FPS}^{6}$. Satisfizeram, ainda, os requisitos de transmissão de imagem pelo sistema $\mathrm{RGB}^{7}$ e funcionamento com endereço $\mathrm{IP}^{8}$. Estas câmaras, alimentáveis em 11 volts por intermédio de transformador, também dispõem, em opção, da funcionalidade $\mathrm{POE}^{9}$ não instalada.

Beneficiando-se do pé-direito livre dos átrios (12 metros) foi possível uma localização aproximadamente zenital das câmaras com as seguintes vantagens: 


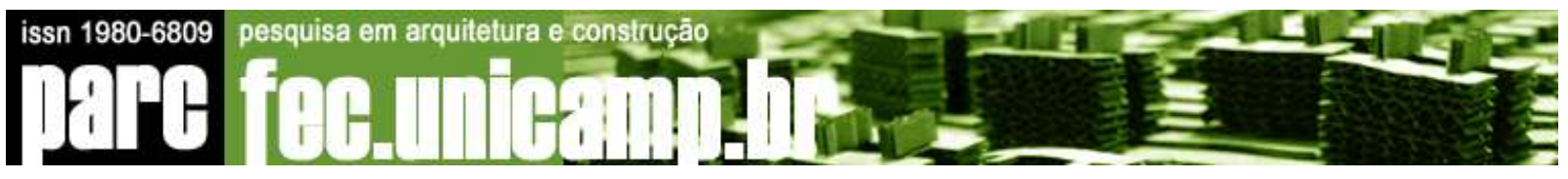

1) redução dos utilizadores a dimensões mínimas, facilitando a leitura e interpretação planimétrica dos trajectos registados;

2) minimização da possibilidade de reconhecimento da identidade dos utilizadores para salvaguarda das questões de privacidade;

3) redução da mútua ocultação visual dos utilizadores, factor inversamente proporcional ao das cotas de colocação das câmaras;

4) captação das cenas segundo enquadramentos gerais abarcando a globalidade das interacções espaciais.

$\mathrm{Na}$ instalação das câmaras, os ângulos de observação foram previamente examinados no software 3D World Builder ${ }^{10}$ permitindo escolher as opções mais vantajosas (FIG. 5).

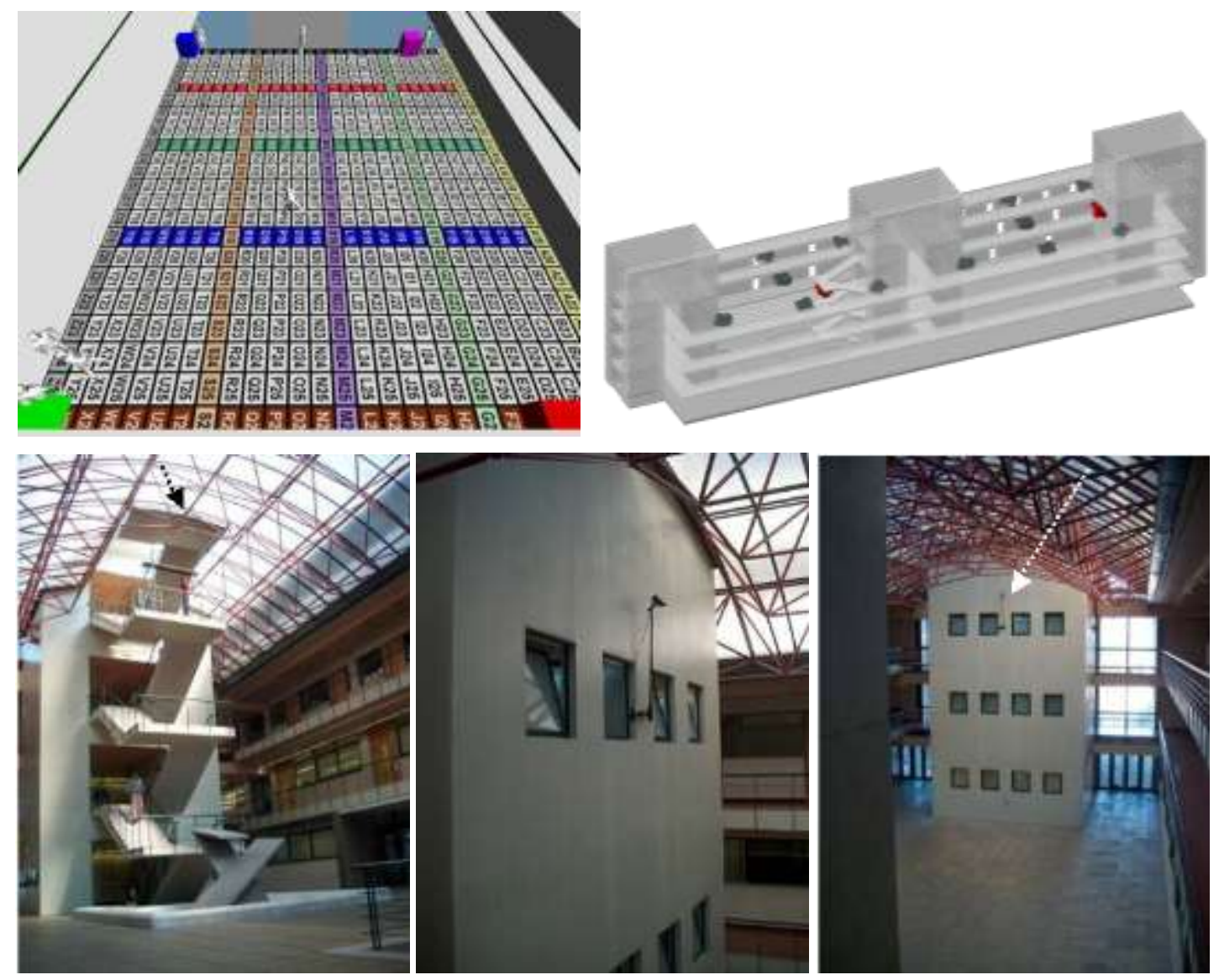

FIGURA 5: Simulação da localização da câmara 2 (Átrio Norte) produzida pelo software 3D World Builder $^{10}$ (suspensa da torre de acessos) (cima/esquerda). Esquema volumétrico do átrio central. Hipóteses iniciais de localização das câmaras nos Átrios Sul e Norte (câmaras cinza) e locais seleccionados (câmaras vermelhas) (cima/direita). Montagem da câmara no Átrio Sul (baixo/esquerda). Câmara instalada no átrio Norte (baixo/centro/direita). 


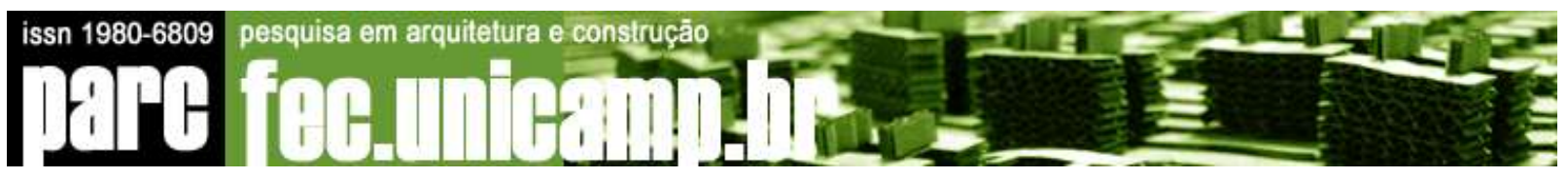

A recolha de imagens (com recurso ao software Recorder ${ }^{10}$ ) (FIG. 6) ocorreu desde Novembro de 2007 incidindo sobre distintos cenários de uso, i.e., ocupações espaciais durante intervalos de tempo determinados, caracterizadas por cargas de utilização específicas, definidas pelo número de utilizadores e tipo de uso. Foram registados cenários de uso corrente em ambos os átrios e eventos no Átrio Norte. As gravações incidiram, sobretudo, nos períodos lectivos, aqueles com maior carga de utilização. O desenvolvimento da versão beta do algoritmo incidiu sobre o intervalo de utilização diária mais intenso: 8h-18h.

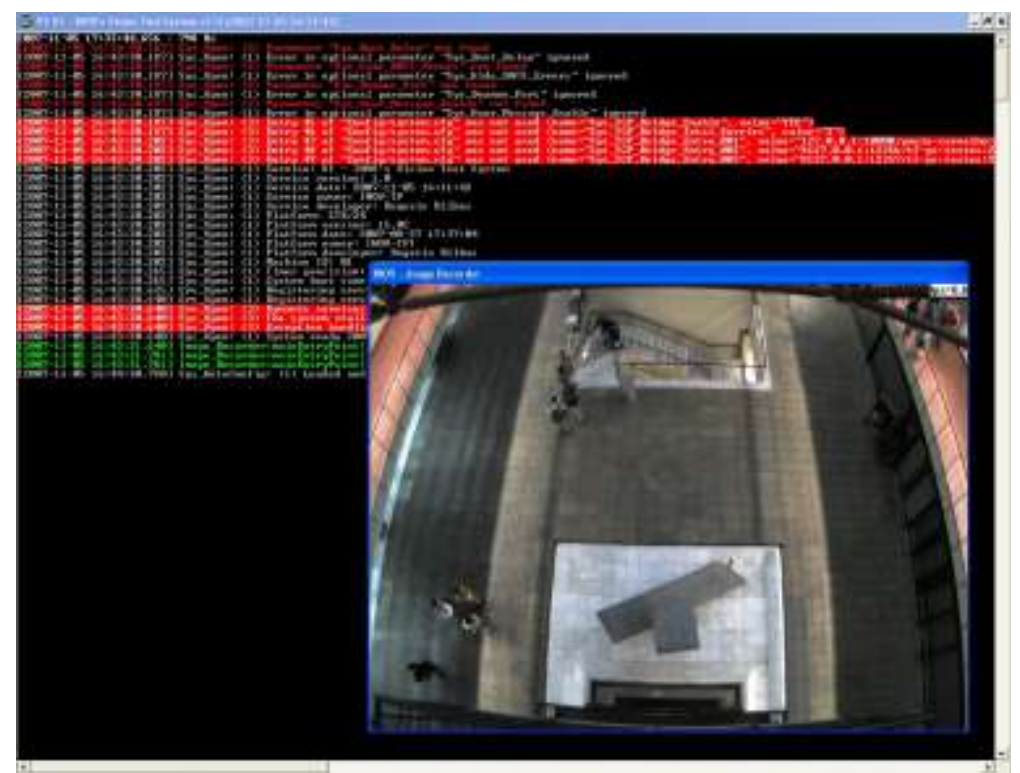

FIGURA 6: Interface do software de gravação Recorder (INOV ${ }^{5}$. Átrio Sul.

Cenário de uso corrente.

Do processamento das imagens (FIG. 7) resultaram mapas de ocupação (constituídos por manchas) e mapas de fluxos (constituídos por linhas) (FIG. 8).Os primeiros desdobraramse em dois: ocupação por tempo e ocupação por número de pessoas. A primeira reporta-se ao tempo de permanência no átrio definido em percentagem relativamente ao intervalo de observação; a segunda, à contabilização dos utilizadores nos espaços observados. Os mapas de fluxos registam os seus trajectos. Cada mapa corresponde a um índice de mobilidade.O cruzamento entre índices de ocupação permitiu estabelecer correspondências entre a duração das presenças e o número de utilizadores observados. 

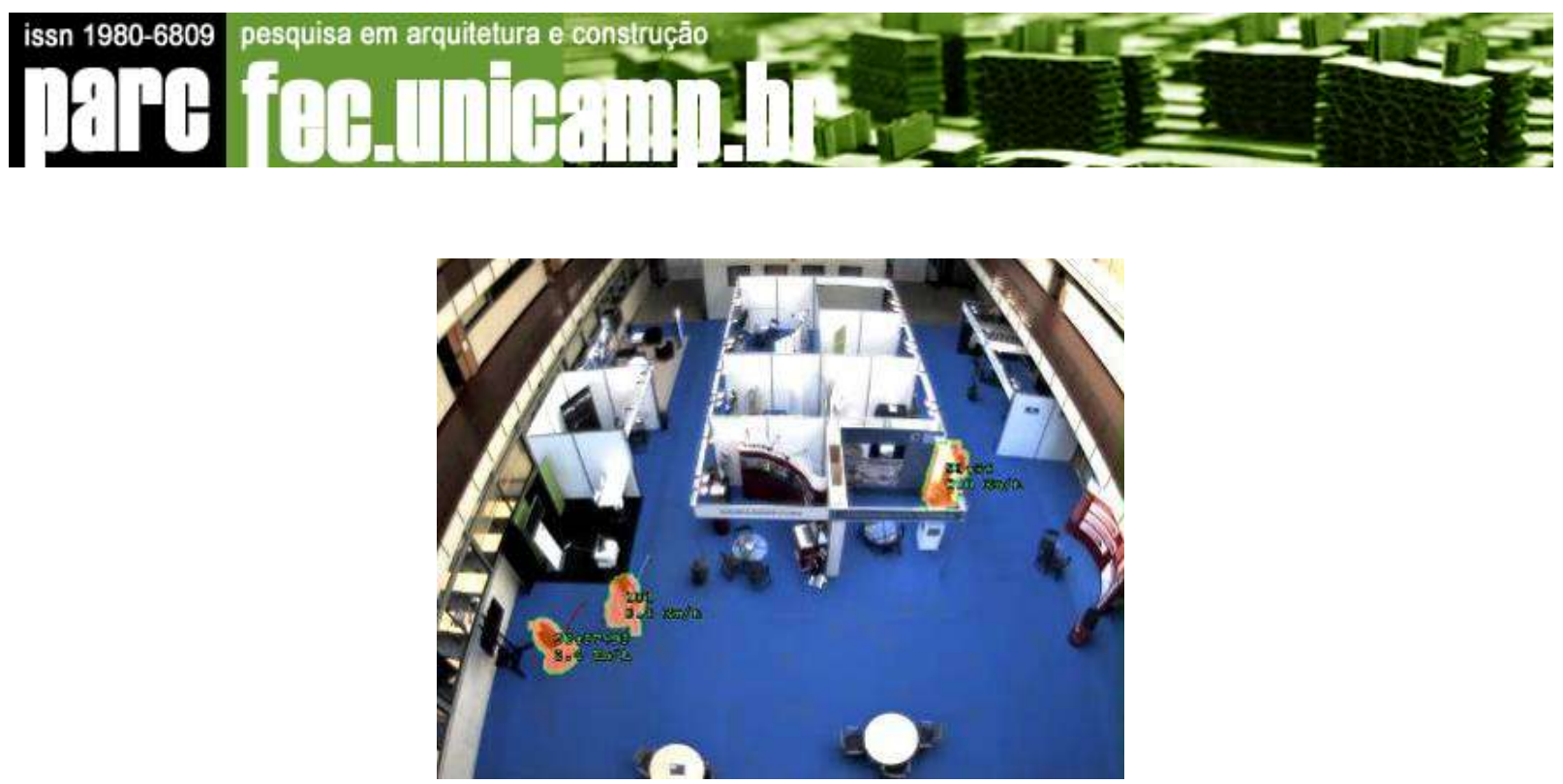

FIGURA 7: Fotograma do vídeo do detector (evento no Átrio Norte). O detector constitui o processo através do qual o algoritmo "aprende" a distinguir o fundo da cena (parte fixa) dos alvos em movimento. Cada utilizador é identificado por um ID (IDentification number) e as suas posições a cada momento no espaço bidimensional da imagem são definidas segundo coordenadas xy. Esta é a base a partir da qual se podem deduzir informações posteriormente.

As manchas de ocupação foram representadas na escala de cor RGB (FIG. 8). O valor máximo do índice (para o intervalo de observação) corresponde ao vermelho puro. Nos mapas de fluxos, a introdução de transparência nas linhas permitiu identificar sobreposições assinalando assim zonas de passagem mais frequentes. No intervalo de estudo $8 \mathrm{~h}-18 \mathrm{~h}$, os mapas foram calculados para cada hora e para o total das horas observadas.

Os índices de ocupação (ALL) foram decompostos em sub-índices de acordo com o estado de mobilidade dos utilizadores: STOPPED (utilizadores estacionados) e MOVING (utilizadores em movimento). A ocupação por tempo considerou: uma ocupação mais constante, relativa aos utilizadores parados (velocidade=0); uma ocupação mais fugaz, instante em que os utilizadores pisam um determinado local (velocidade $\neq 0$ ). Semelhantemente, na ocupação por número de pessoas, STOPPED corresponde ao número de pessoas estacionadas, i.e., com velocidade=0; e MOVING ao número de pessoas em movimento, i.e., IDs que respeitaram a condição velocidade $\neq 0$ (FIGS. 10 e 12). Nos fluxos, os sub-índices STOPPED distinguiram trajectos onde se registassem, pelo menos uma vez, velocidade nula e NONSTOPPED a trajectos onde a velocidade nula nunca fosse assinalada. Nos mapas de ocupação, a informação refere-se à ocupação traduzida em tempo ou número 


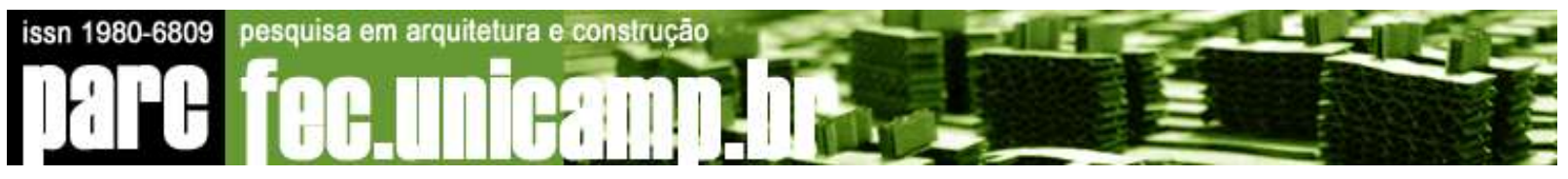

de pessoas (cor/intensidade) e sua distribuição espacial (localização/extensão das manchas) no espaço observado.

Os mapas de ocupação são mapas estatísticos. Permitem compreender as dinâmicas de mobilidade reportadas ao grupo. Descrevem, em termos quantitativos, o modo como o espaço é ocupado em função do tempo de permanência dos utilizadores ou do seu número. Tais contagens não consideram cada movimento individualmente (como sucede nos mapas de fluxos) mas sim desagregadamente, ou seja, os resultados dos mapas de ocupação são consequência de contagens transversais ao conjunto de movimento individuais ocorridos no espaço observado. Por isso constituem sínteses sobre a apropriação do espaço facilitando a construção de uma ideia global quanto à descrição desse processo de apropriação.

Contrariamente, os mapas de fluxos não são mapas estatísticos. As teias obtidas resultam do somatório dos fluxos individuais. Por esse motivo, estes mapas são particularmente úteis no detalhe das trajectórias de navegação espacial, nomeadamente, no respeitante à ocorrência de comportamentos exploratórios individuais, menos habituais, difíceis de detectar nos padrões estatísticos dos índices de ocupação reportados aos comportamentos de grupo (FIG. 8).

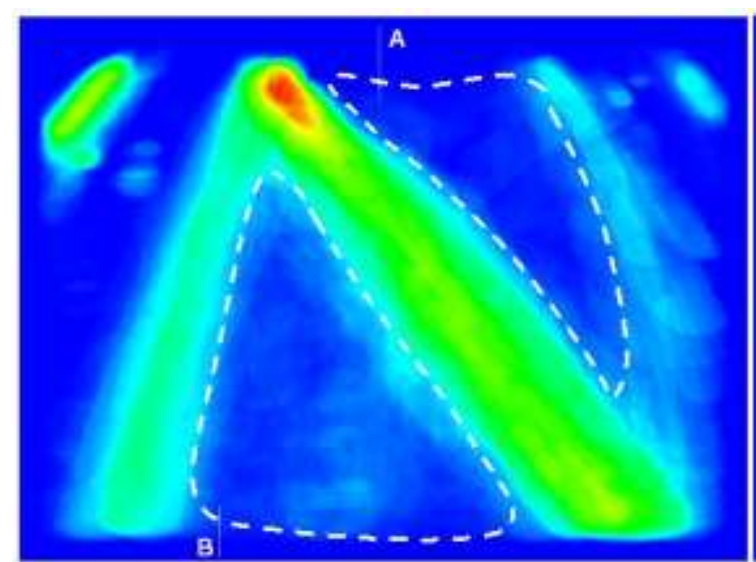

OCUPACEAO POR NÜMERO DE PESSOAS

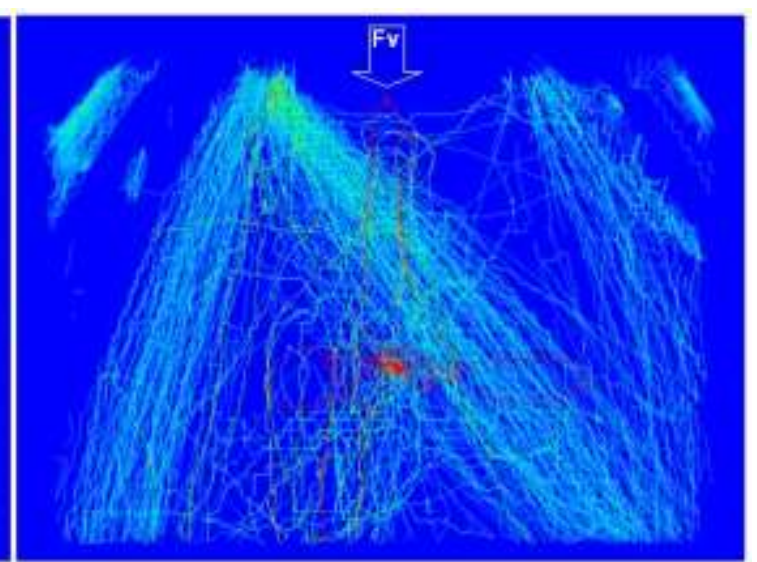

FLuxos

FIGURA 8: Átrio Norte: cenário de uso corrente. Mapa de ocupação por número de pessoas (ALL) e mapa de fluxos (ALL) referentes ao período das 13 horas. No mapa de fluxos pode observar-se em pormenor as trajectórias espaciais dos utilizadores como por exemplo, o fluxo vermelho (Fv) cuja incidência não é perceptível no mapa de ocupação e as teias de fluxos menos densas que ocorrem nas zonas A e B do mapa de ocupação. 


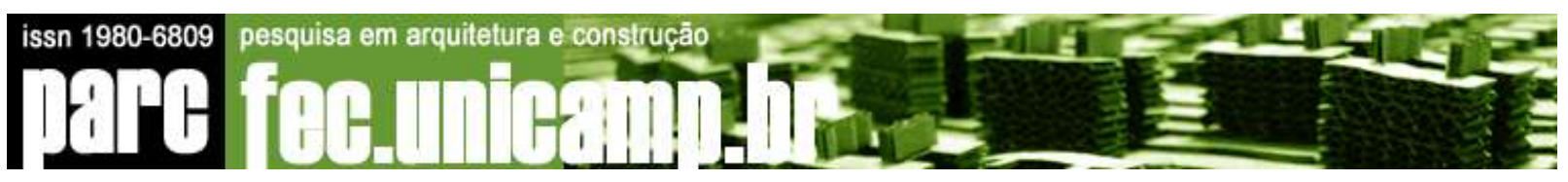

Os mapas de ocupação por tempo foram representados segundo uma escala dinâmica e uma escala fixa (FIG. 9). Na escala dinâmica, para cada hora, é calculado o valor máximo do índice, i.e., para cada mapa de ocupação, o vermelho puro apresenta um tempo de ocupação máximo diferente, sendo igualmente diferente, a distribuição dos valores intermédios pela escala cromática. A escala fixa estabelece um referencial idêntico para todos os mapas. A escala dinâmica apresenta como vantagem a possibilidade de captar baixos tempos de ocupação pois define uma escala de valores própria para cada cada período de observação, por isso mesmo apenas permite estabelecer comparações directas entre os valores máximos dos mapas. A escala fixa permitir estabelecer comparações directas entre horas ainda que com uma gama dinâmica menor em casos de baixa ocupação por tempo. Nos mapas relativos ao número de pessoas apenas se justificava a escala dinâmica.

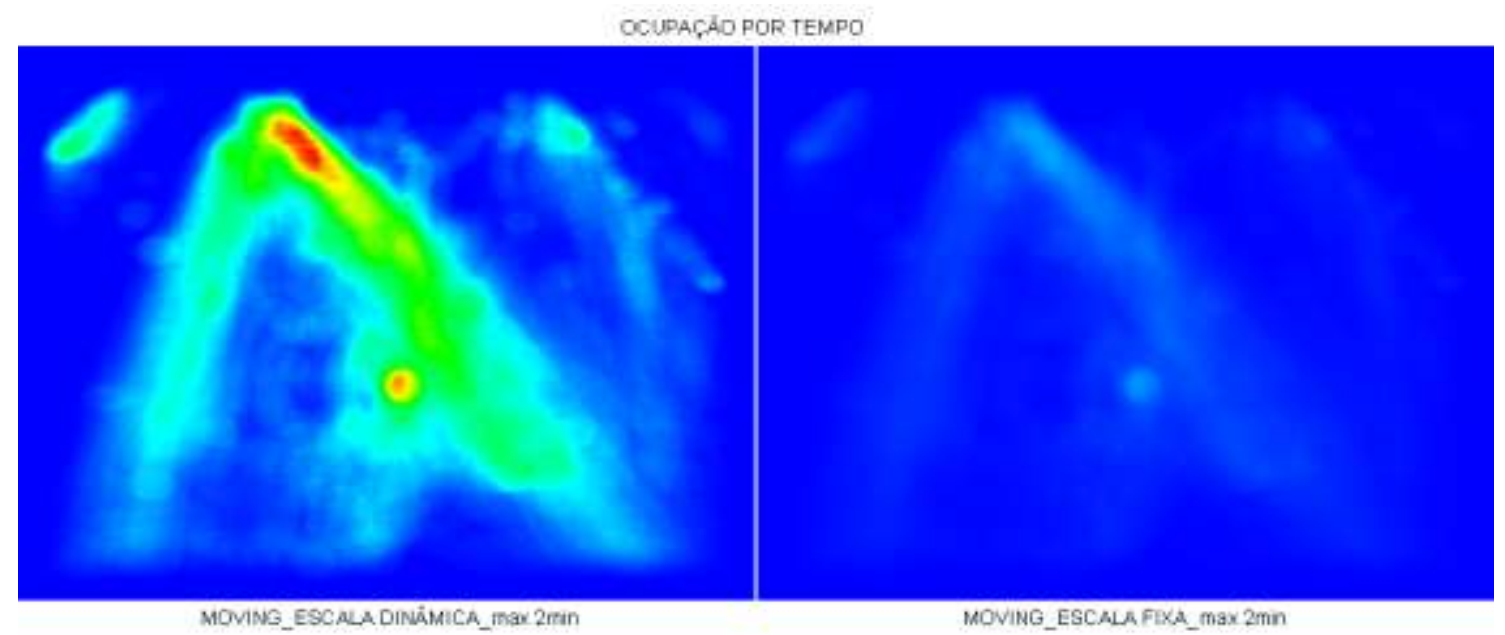

FIGURA 9: Átrio Norte: cenário de uso corrente. Mapa de couapção por tempo referente ao período das 13 horas. Escala dinâmica (esquerda) e escala fixa (direita).

A análise assentou em duas abordagens complementares: uma abordagem de natureza qualitativa, baseada na avaliação da intensidade e incidência espacial dos índices no átrio, viabilizada pela análise dos padrões de ocupação expressos nos mapas; e uma abordagem de natureza quantitativa, baseada na comparação e análise da evolução dos valores máximos para cada índice para um dado intervalo de observação. Por último, analisaram-se as correlações entre a configuração da ocupação/movimento e a configuração do espaço associadas a cada cenário de uso estudado. 


\section{RESULTADOS}

Os resultados apresentados reportam-se aos cenários de uso corrente dos Átrios Sul e Norte do DECivil. Correspondem aos mapas relativos ao período global de observação (onze horas). Os mapas definem-se segundo uma escala dinâmica no sentido de permitirem uma leitura mais detalhada da distribuição espacial dos índices de ocupação. Sendo assim, em termos quantitativos, apenas são directamente comparáveis os valores máximos dos índices (ilhas vermelhas).

Os padrões de ocupação revelam uma distribuição espacial do número de utilizadores notoriamente assimétrica (FIG. 10). Em ambos os átrios, os utilizadores concentram-se essencialmente no lado nascente. No Átrio Sul o lado nascente estabelece contiguidade directa com o átrio de entrada no edifício caracterizada por grande permeabilidade fisíca e visual entre os dois espaços. A fonte desactivada (rever FIG. 3), elemento central deste átrio, constitui um ponto preferencial de encontro e de controlo visual relativamente a quem entra ou sai do edifício. Também a nascente, e ainda a Sul, localiza-se o bar, um dos serviços do DECivil diariamente mais utilizados pela população académica do IST. A esplanada do bar constitui também um outro acesso preferencial factor que, a par dos anteriores, contribui para compreender a concentração dos utilizadores a nascente. A proximidade das escadas de acesso aos auditórios no piso inferior gera uma das ramificações no átrio da ocupação nascente, aliás mais acentuada em MOVING. No Átrio Norte, a concentração de utilizadores a nascente justifica-se essencialmente pela necessidade de circulação entre as duas torres de acesso, central e norte, para quem acede ao edifício a partir do átrio de entrada.

A rarefacção de utilizadores a poente justifica-se pelo facto dos átrios não comportarem polaridades funcionais suficientemente fortes para competir com o lado nascente. No Átrio Sul, a poente localiza-se um museu, com um horário de funcionamento muito restrito e um conteúdo expositivo pouco apelativo. No Átrio Norte, os estúdios de Arquitectura localizados a poente servem uma população estudantil activa mas reduzida pelo que não é uma área muito percorrida. 


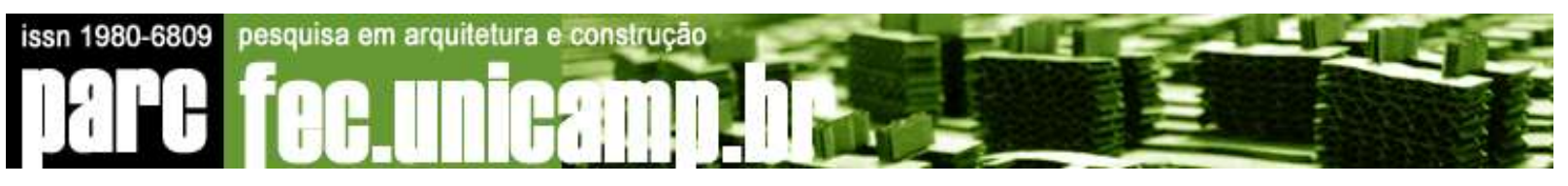

ALL_max_770
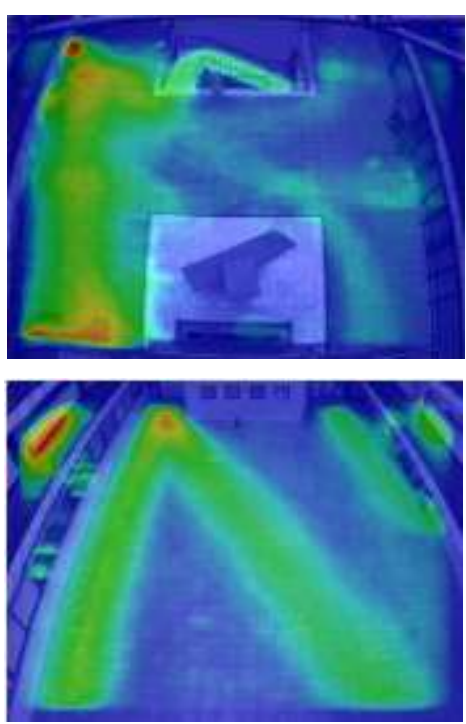

ALL_max_616
Átrio Sul - Ocupação por Número de Pessoas MOVING_max_439
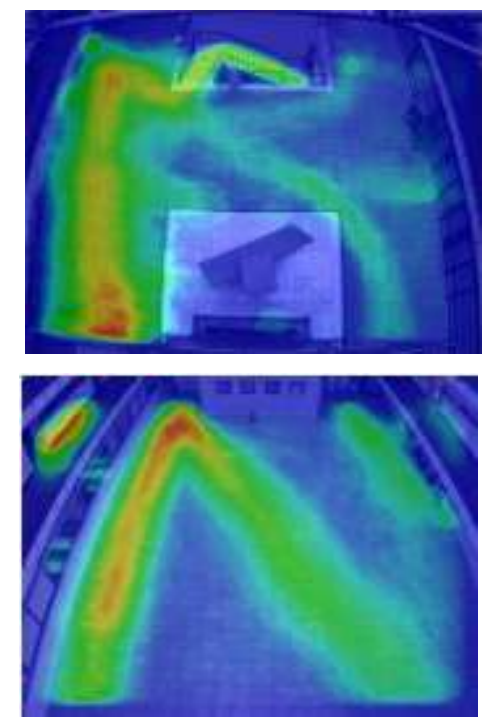

MOVING_max_429
STOPPED_max_752
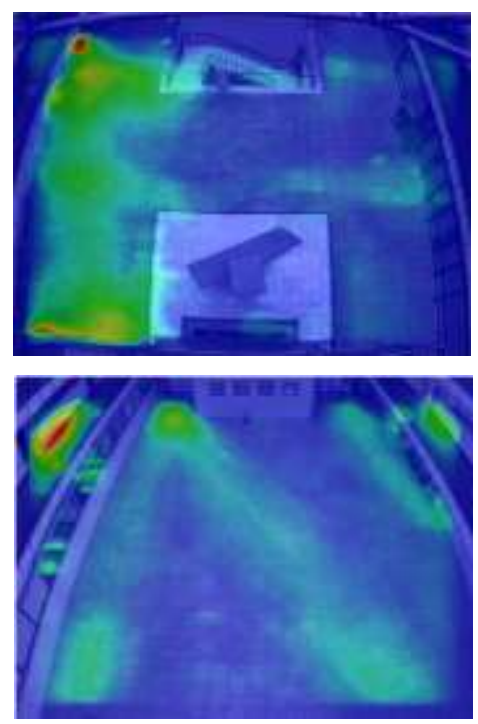

STOPPED_max_440

Átrio Norte - Ocupação por Número de Pessoas

FIGURA 10: Átrio Sul e Átrio Norte. Cenário de uso corrente. Mapas de ocupação por número de pessoas relativos à globalidade do período de observação (onze horas) sobrepostos à imagem de teste.

Os padrões revelaram ainda uma distribuição dos utilizadores nos átrios segundo as suas diagonais. Distribuição mais notória no Átrio Norte estabelecida entre o vértice sul/nascente (ponto mais próximo da entrada/saída do edifício) e o refeitório, vértice oposto, circuito muito percorrido, essencialmente durante as horas de almoço, dado tratar-se dum serviço com capacidade de atracção sobre toda a população do campus. No Átrio Sul, a ocupação segundo a diagonal (semelhantemente orientada como a diagonal norte) traduz um circuito alternativo resultante de alguma polarização exercida pelos estúdios de Arquitectura localizados a Norte. Note-se a acentuação da mancha de ocupação em MOVING.

Os valores máximos do índice revelaram que o Átrio Sul comporta maior número de utilizadores (ALL_770) do que Átrio Norte (ALL_616). Revelam ainda que, proporcionalmente, o Átrio Sul tem maior capacidade de fixação dos utilizadores do que o Átrio Norte (a diferença 


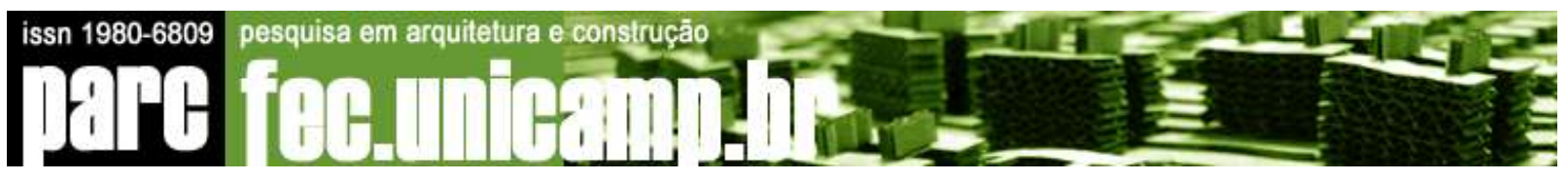

entre os valores máximos de STOPPED e MOVING é maior a Sul). Essa capacidade é facilmente justificada pelas contiguidades funcionais do Átrio Sul (bar e acessos) e pela possibilidade de sentar/permanecer que a fonte oferece associada à elevada permeabilidade visual que caracteriza o Átrio Sul, particularmente a nascente, como demonstra o grafo de visibilidade $^{11}$ (FIG. 11). Repare-se ainda que os valores máximos se localizam a Sul no acesso ao bar e a Norte, no vértice sul/nascente, zona pontual igualmente destacada por elevados valores de integração visual12 (FIG. 11-A).

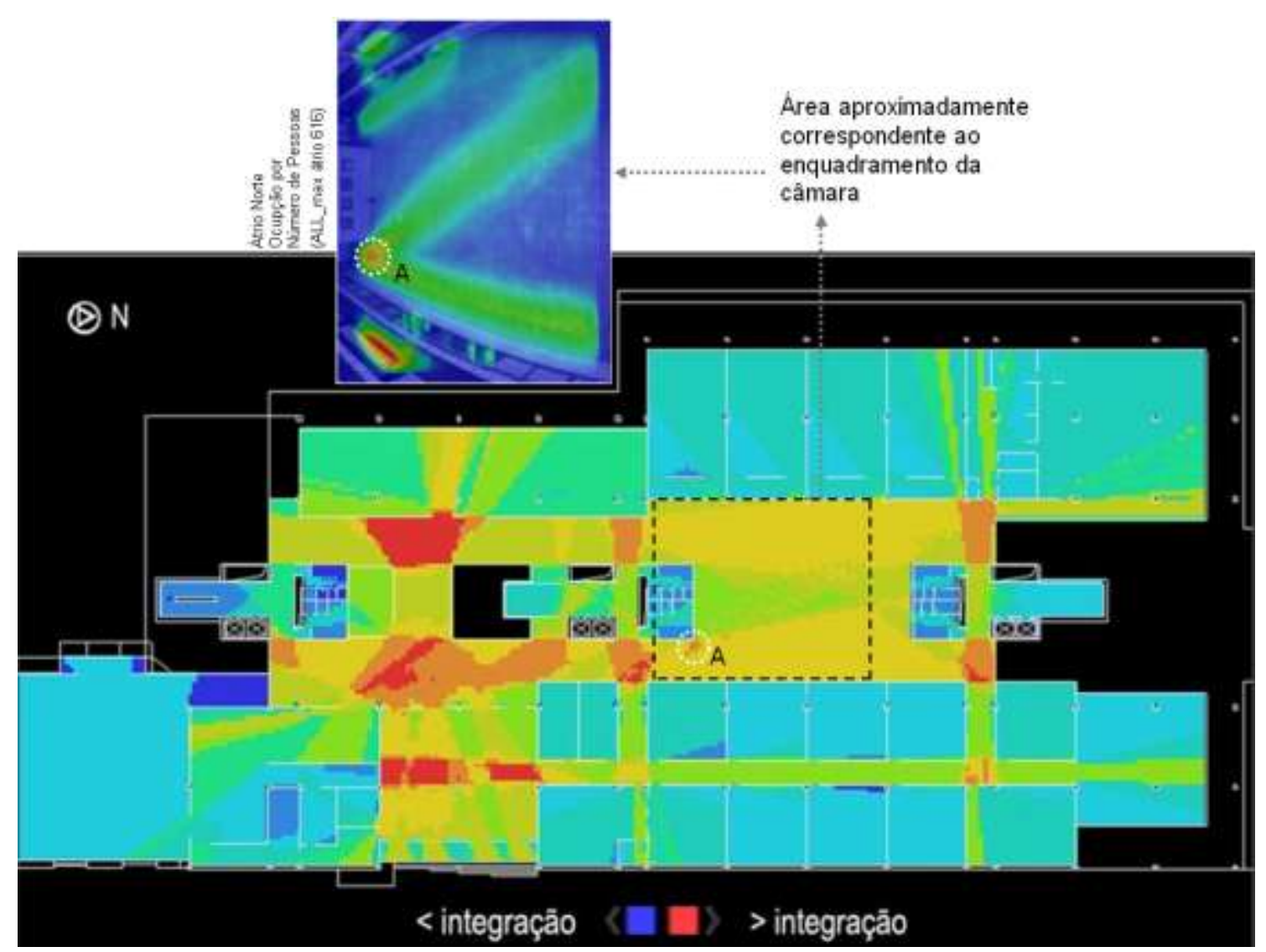

FIGURA 11: Grafo de visibilidade ${ }^{11}$ do piso térreo do DECivil (DephtMap, Alasdair Turner). A - zona de maior integração visual no Átrio Norte espacialmente coincidente com os máximos dos índices de ocupação.

Essa capacidade de fixação é corroborada pelos tempos de ocupação mais elevados a Sul (ALL_7 min) do que a Norte (ALL_2 min) (FIG. 12) e, ainda, pelo facto dos utilizadores estacionados permanecerem mais a Sul (STOPPED_max_6 min) do que a Norte (STOPPED_max_2 min). Note-se também a acentuada discrepância entre MOVING e 


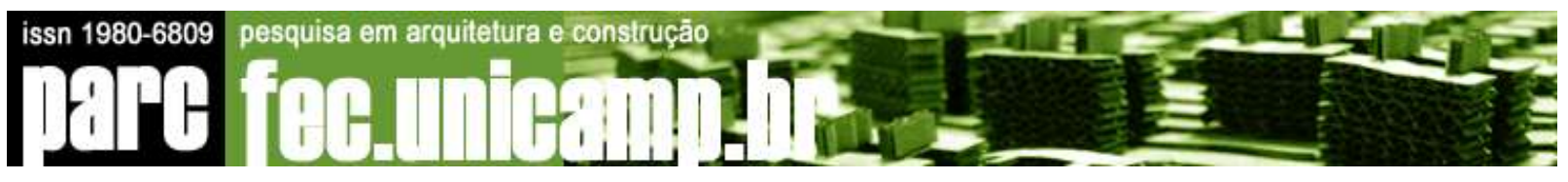

STOPPED a Sul enquanto que, a Norte, os sub-índices registam máximos muito próximos. Deste modo, o Átrio Norte revela-se essencialmente um espaço de passagem enquanto o Átrio Sul assume um carácter de estadia. Outro aspecto a salientar é o facto dos valores máximos da ocupação por tempo não coincidirem espacialmente com as manchas relativamente às concentações de utilizadores a Sul. Pelo contrário, distribuem-se por outros pontos do Átrio revelando uma permanência associada a grupos mais pequenos dispersos pelo espaço. A Norte, pelo contrário, tempos de ocupação mais elevados e maiores concentrações de utilizadores registam maior coincidência espacial contribuindo para consolidar a ideia que o átrio é apropriado segundo zonas bem definidas.

ALL_max_7 min
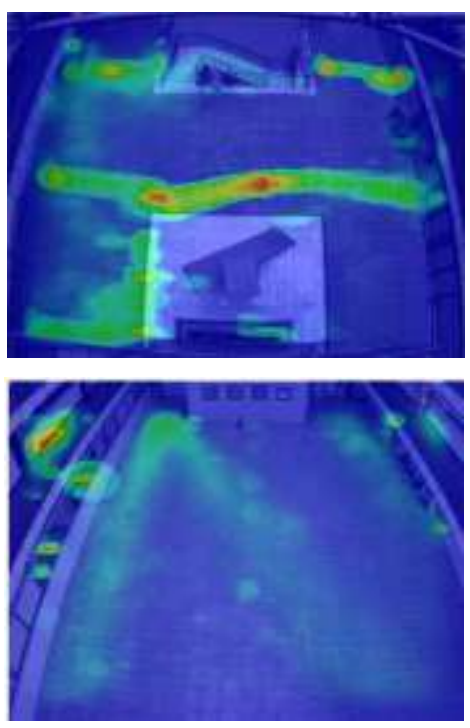

ALL_max átrio*_2 min
Átrio Sul - Ocupação por Tempo MOVING_max_<1 min
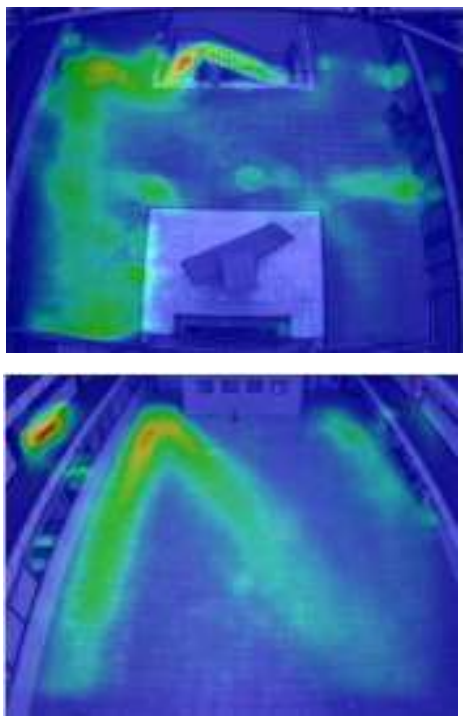

MOVING_max átrio*_1 min Átrio Norte - Ocupação por Tempo
STOPPED_max_6 min
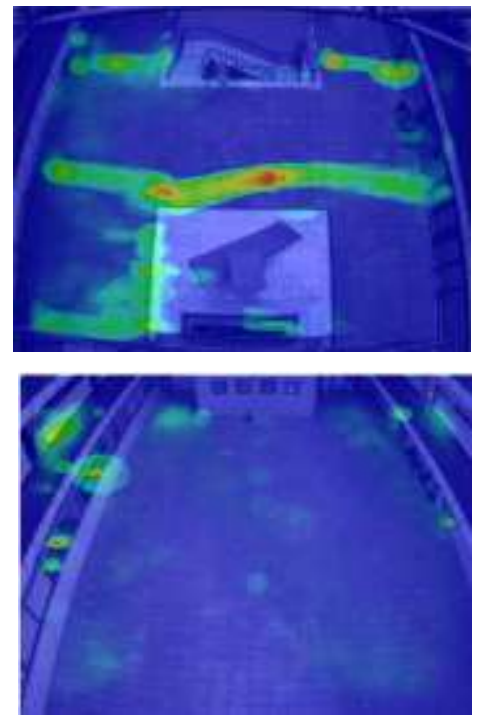

STOPPED_max átrio*_2 min

* Os valores máximos reportam-se ao átrio correspondendo aos valores cromáticos mais próximos do vermelho.

FIGURA 12: Átrio Sul e Átrio Norte. Cenário de uso corrente. Mapas de ocupação por tempo relativos à globalidade do período de observação (onze horas) sobrepostos à imagem de teste.

As diferenças de configuração entre as ilhas de ocupação dos dois átrios exprimem comportamentos espaciais diferenciados. A Sul, as ilhas alargam-se, registando irregularidades na sua densidade (denotando variação do número e tempo de permanência dos utilizadores). A concentração nascente dispersa-se dando continuidade a outras ilhas; a 


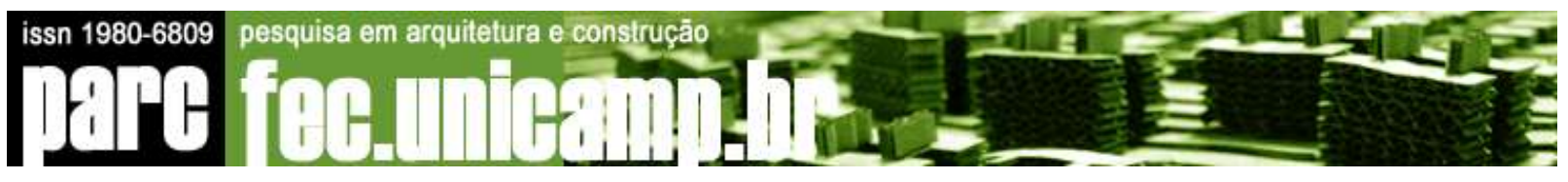

Norte, a ocupação define-se segundo manchas cromaticamente mais coesas e mais restritas em área. O primeiro caso conota-se com movimentos que se distribuem e evoluem pelo átrio. Correspondem a comportamentos espaciais mais exploratórios. O segundo caso corresponde a movimentos mais localizados, direccionados e orientados segundo um objectivo. Conotamse com meros atravessamentos do espaço. Tal confirma-se pela análise dos padrões de fluxos (FIG. 13).

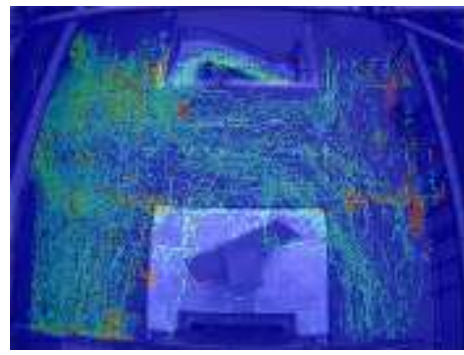

\section{$\mathbf{N}$}

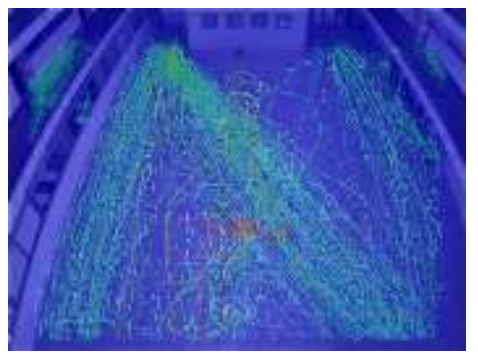

FIGURA 13: Mapas de fluxos (ALL) sobrepostos às imagens de teste. Cenários de uso corrente. Correspondem a picos de ocupação (positivos) por número de pessoas. Átrio Sul (uso corrente): $11 \mathrm{~h}$. Átrio Norte (uso corrente): $13 \mathrm{~h}$.

A análise da evolução dos valores máximos dos índices de ocupação, hora a hora, permitiu aprofundar o entendimento das dinâmicas de mobilidade nos espaços observados. Foi possível identificar a variação dos índices e sub-índices ao longo do intervalo de observação, caracterizar e relacionar a variação horária das curvas de cada índice, identificar picos de ocupação e correlacioná-los entre si.

Sumariamente foi possível concluir que no Átrio Sul a evolução do número de utilizadores se caracterizou por uma dicotomia entre valores globalmente mais elevados, registados entre as $8 \mathrm{~h}$ e as $11 \mathrm{~h}$ e, valores mais baixos, registados a partir das 12h (FIG. 14). O período inicial caracterizou-se pelo progressivo crescimento dos números máximos de utilizadores, enquanto o segundo evoluiu mais linearmente. As $12 \mathrm{~h}$ marcaram uma fronteira 


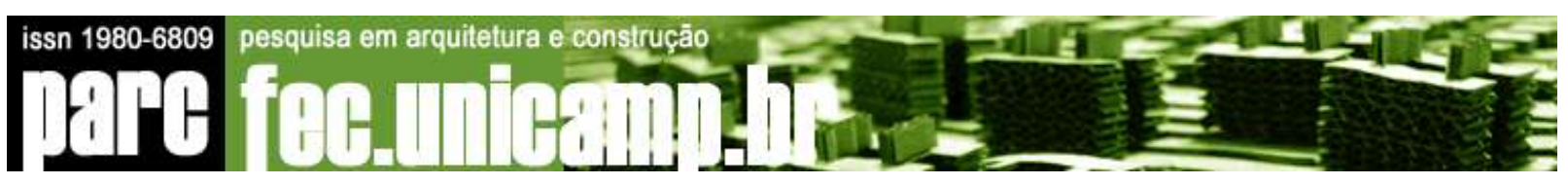

nítida entre as duas fases de evolução das curvas registando o menor número de utilizadores para ALL (144) e a quebra mais acentuada para os sub-índices. As $11 \mathrm{~h}$ registaram o pico máximo de 322 utilizadores para ALL e 303 para STOPPED enquanto MOVING registou apenas 160.

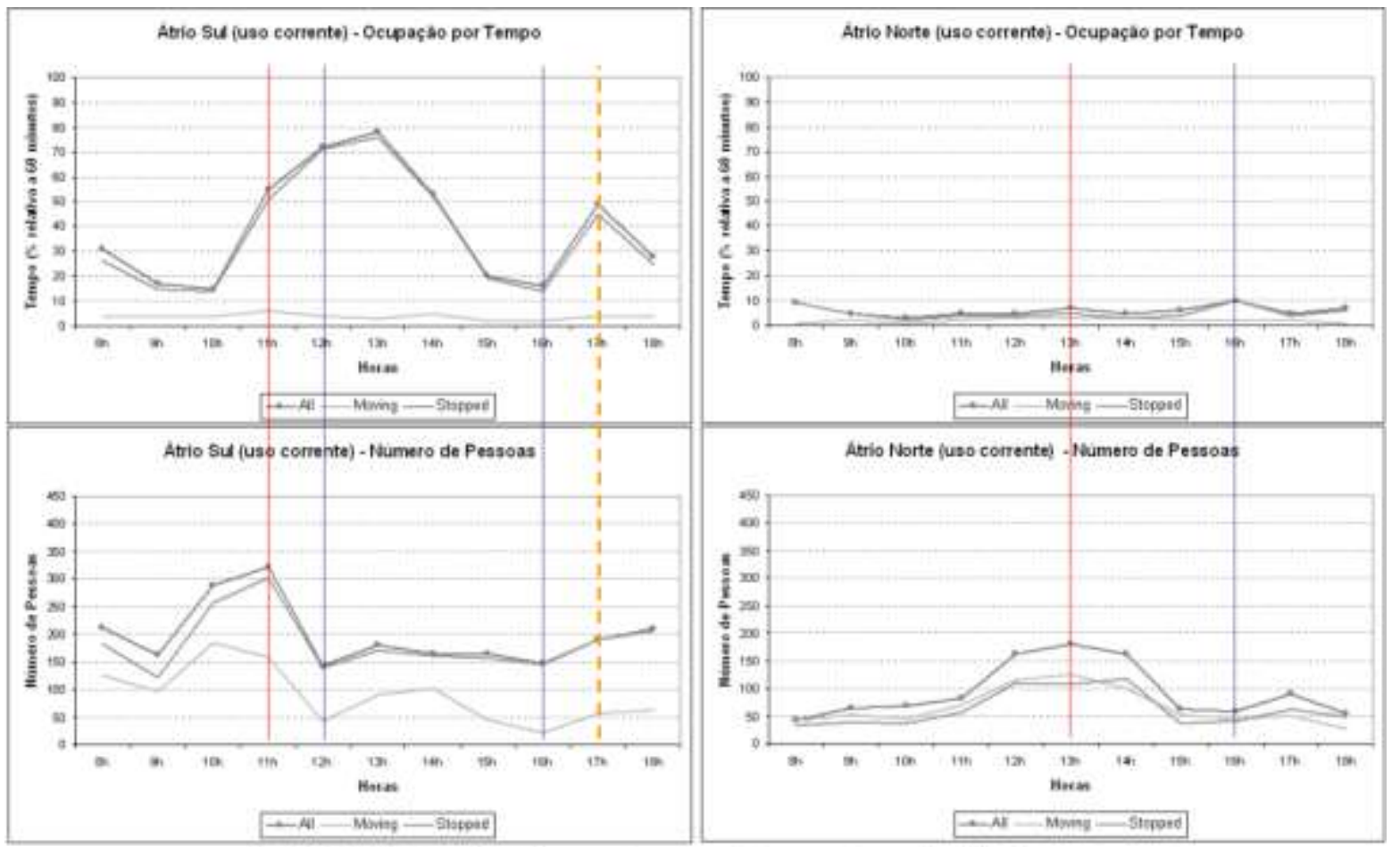

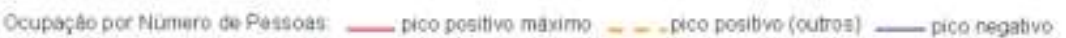

FIGURA 14: Variação horária dos valores máximos para os índices de ocupação: tempo e número de pessoas. Relação entre os respectivos picos de ocupação.

A assimetria que caracterizou a evolução do índice ocupação por número de pessoas não encontrou reflexo directo na evolução do índice ocupação por tempo. A quebra no número de utilizadores, registada às $12 \mathrm{~h}$, e mantida nas horas sequentes, correspondeu a um aumento do tempo de ocupação do átrio atingindo o valor máximo às $13 \mathrm{~h}$. Maior concordância do sentido evolutivo das dinâmicas de ocupação registou-se a partir das 14h. Nesta fase, o declínio dos tempos de ocupação encontrou correspondência nos números mais baixos de utilizadores presentes no átrio e as 16h (um dos períodos com menor número de utilizadores) coincidiram com menores tempos de ocupação do átrio. Às 17h, a fase de crescimento do número de utilizadores, correspondeu a um pico secundário de ocupação por tempo. 


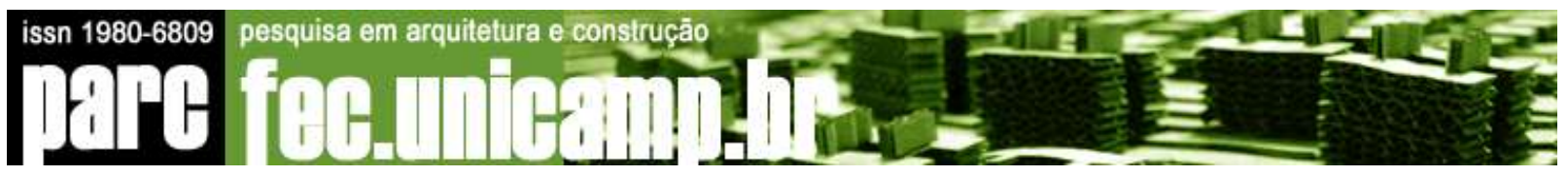

No Átrio Norte a evolução das curvas de ocupação por número de pessoas caracterizarou-se pela ascensão e declínio dos valores máximos do índice tendo como ponto de charneira as $13 \mathrm{~h}$. Pode constatar-se a proximidade entre as curvas MOVING e STOPPED e, na maior parte das horas, a predominância da curva MOVING sobre a curva STOPPED significando que o maior número de utilizadores presentes no átrio resultou mais do contributo dos utilizadores em trânsito que dos utilizadores estacionados. As $13 \mathrm{~h}$ registaram o principal pico de ocupação do átrio com o número máximo de 181 utilizadores para ALL e 125 para MOVING. STOPPED registou um máximo de 108 utilizadores.

Ao longo das horas de observação, a variação do número de utilizadores presentes no átrio correspondeu a tempos de ocupação relativamente estáveis mas efémeros. O pico de utilizadores registado às $13 \mathrm{~h}$ não encontrou equivalente nos respectivos tempos máximos de ocupação relativamente idênticos ao longo das horas. No entanto assinalaram-se ligeiros acréscimos (cerca de 1 minuto) para ALL e STOPPED. MOVING manteve-se inalterável. As 16h, o pico de ocupação por tempo, correspondeu a um dos números de utilizadores mais baixos.

No Átrio Sul, a evolução da ocupação por tempo caracterizou-se pela oscilação e progressão gradual das curvas ALL e STOPPED enquanto MOVING apresentou uma evolução muito mais estável. A ocupação motivada por utilizadores em trânsito foi relativamente pouco significativa e quase invariante. As curvas ALL e STOPPED registaram o pico de ocupação mais elevado às $13 \mathrm{~h}$ com 46 minutos (76\%) para STOPPED e 47 minutos (78\%) para ALL. MOVING registou um tempo máximo de, apenas, 2 minutos (3\%). No Átrio Norte constatou-se a similitude entre os tempos máximos para STOPPED e MOVING e tempos de ocupação muito efémeros. A evolução das curvas ao longo das horas observadas, caracterizou-se pela quase sobreposição e quase linearidade. $O$ pico de ocupação ocorreu às 16h registando o tempo máximo de 6 minutos (10\%) para STOPPED e ALL. Todos os outros tempos máximos de ocupação se situaram abaixo da linha dos $10 \%$.

A análise dos padrões de ocupação permitiu, ainda, identificar a estrutura subjacente à configuração da ocupação/movimento nos átrios, i.e., o conjunto de eixos predominantes, ou mais frequentes, reguladores da forma da ocupação/movimento (FIG. 15). Foi possível identificar o eixo nascente, o grande vector de indução de movimento nos átrios, e dois eixos 


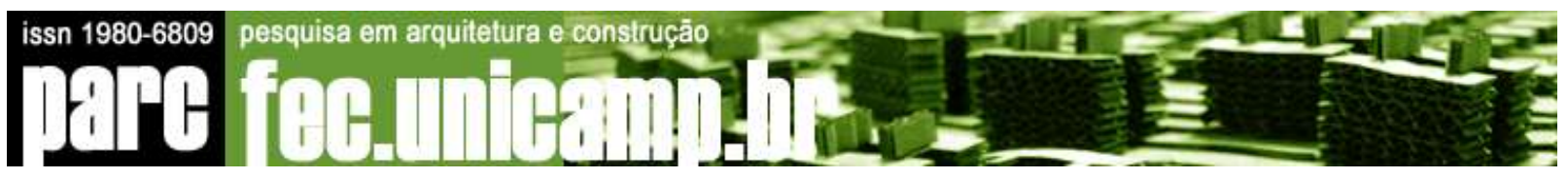

diagonais secundários que "descarregam" no primeiro, convergindo ou emanando dele. Este conjunto traduz as similitudes configuracionais entre os átrios correspondendo aos canais que processam preferencialmente o transvaze de fluxos entre os espaços. Um terceiro eixo, muito menos expressivo, apenas adquire maior definição a Norte sustentado basicamente pela polarização dos estúdios de Arquitectura. A Sul dispersa-se. A canalização de fluxos é maioritariamente desviada segundo a diagonal para (ou a partir do) o eixo nascente.

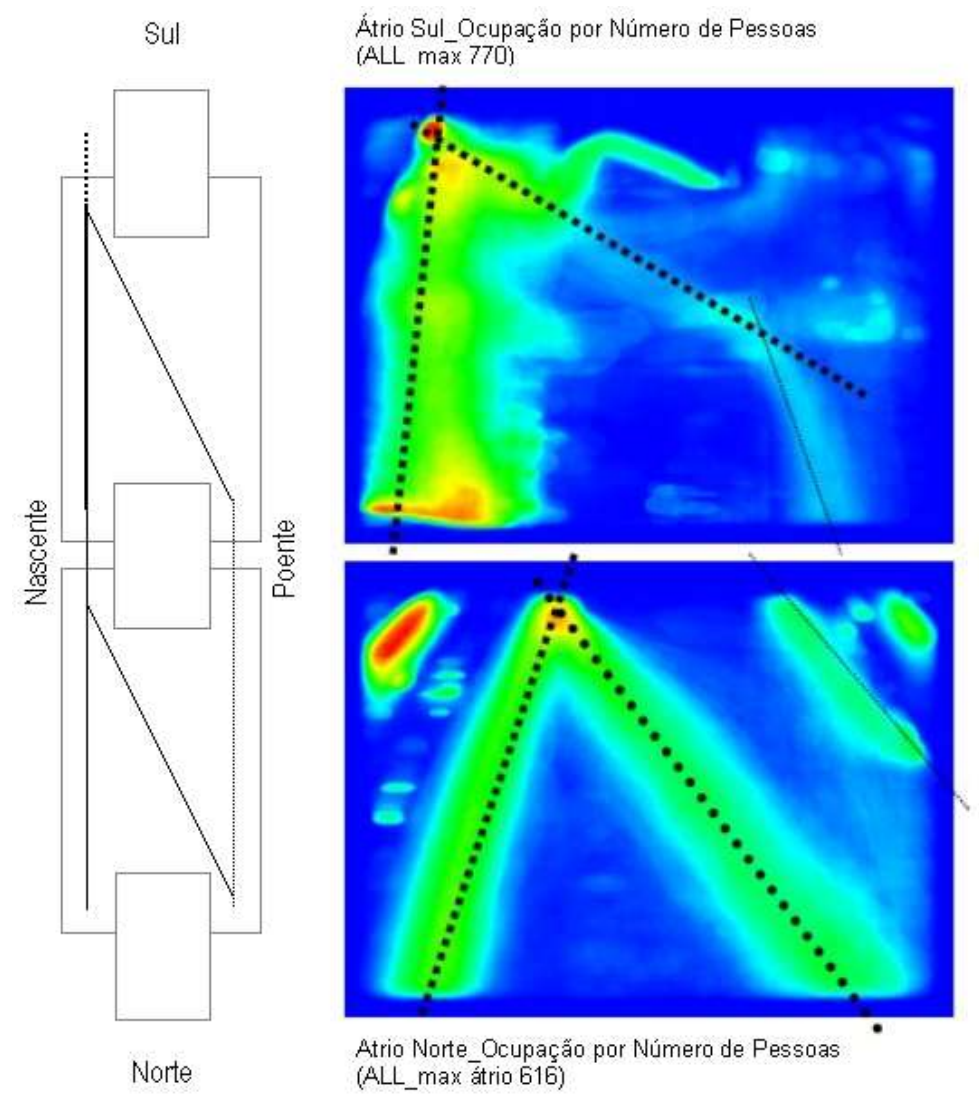

FIGURA 15: Eixos que estruturam a configuração da ocupação/movimento nos átrios.

A estrutura configuracional da mobilidade nos átrios quando confrontada com a configuração axial ${ }^{13}$ do espaço encontra correspondências directas (FIG. 16). Os átrios são regulados pelos eixos de acessibilidade fisíca e visual $A, B, C, D, F, G, H$ e I. A e B constituem os grandes eixos que ligam os dois átrios e nos quais descarregam os eixos transversais. Constituem a estrutura primária da acessibilidade nos átrios de DECivil. Entre ambos, o eixo A é aquele que assume valores de integração mais elevados estabelecendo, assim, uma correlação directa com a configuração da mobilidade marcada pelo eixo 
nascente. No caso do eixo B (apesar de registar valores de integração próximos do valor máximo do sistema axial) a correlação é parcial facto explicável, mais uma vez, pela reduzida capacidade de atracção dos pólos funcionais contíguos ao lado poente dos átrios. Assim, o eixo D (o valor de integração mais elevado para os eixos específicos do Átrio Norte, D e I) assume correlação directa com a diagonal dos padrões de ocupação/movimento.

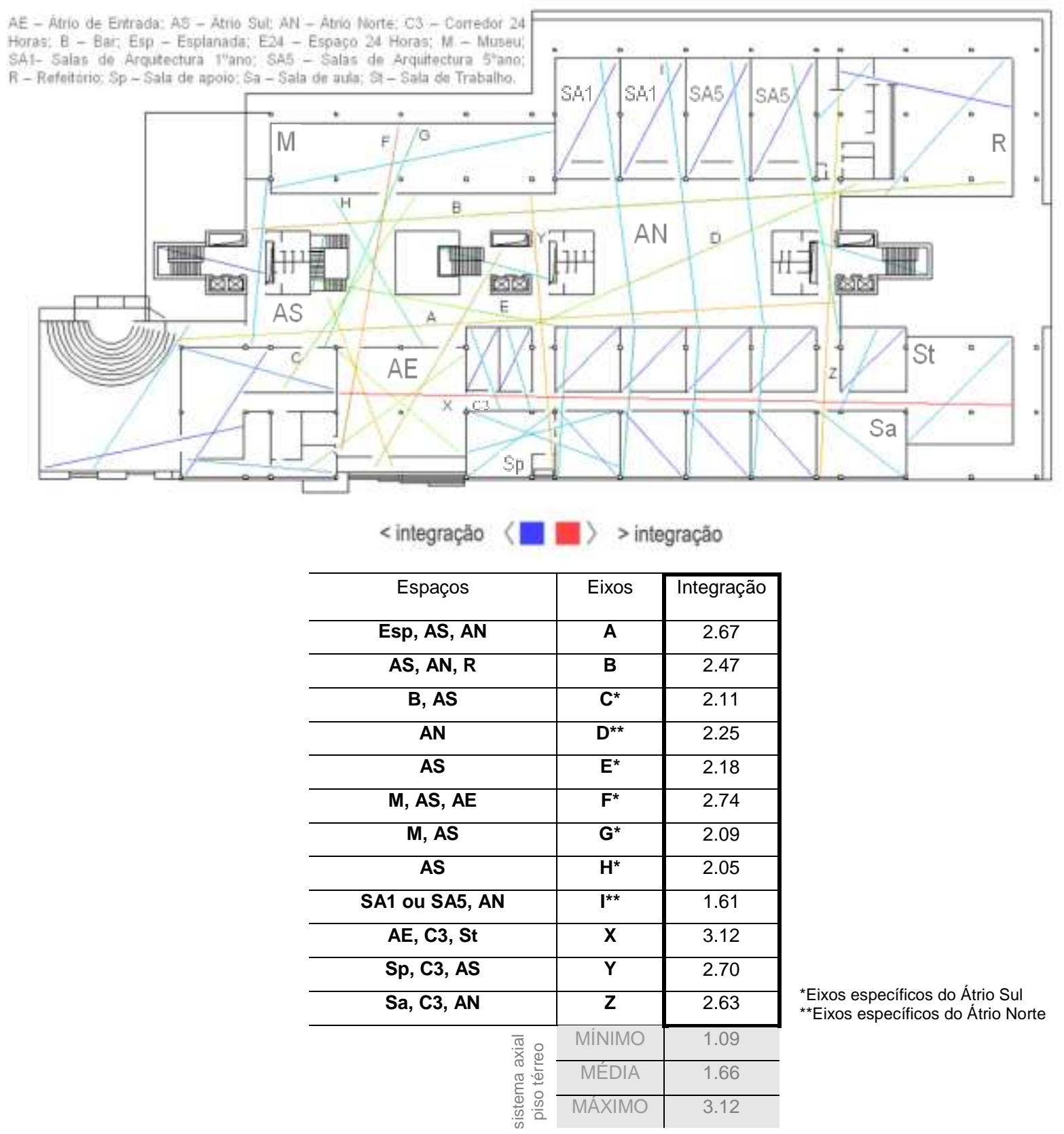

FIGURA 16: DECivil ${ }^{1}$. Piso térreo. Mapa axial. Integração (cima). Valores de integração associados ao mapa axial e espaços associados aos eixos de acessibilidade física e visual (baixo). 


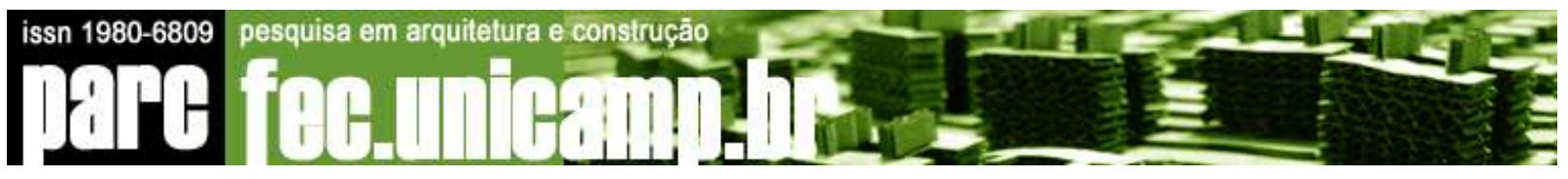

A Sul, o eixo $\mathrm{F}$ (maior valor de integração para os eixos específicos do Átrio Sul, C e E a H) não encontra correspondência na configuração da mobilidade devido à fraca polaridade funcional do museu. Nessa ausência, o eixo C (apesar da sua menor integração) assume correlação explícita com a diagonal de ocupação/movimento neste átrio. $O$ eixo $E$ (o segundo mais integrado do Átrio Sul) contribuirá (conjuntamente com o eixo A) para compreender a concentração dos utilizadores a nascente.

Será ainda de sublinhar a maior profusão de eixos de acessibilidade física e visual no Átrio Sul por contraponto à rarefacção da teia axial do Átrio Norte. Tal profusão é coerente com a expressão da mobilidade nos átrios: uma configuração do movimento mais "alastrada" a Sul, correlacionada com a multiplicidade de eixos de acessibilidade espacial; a Norte, uma configuração do movimento mais "zonada" associada a um número mais restrito de eixos de acessibilidade espacial.

\section{CONCLUSÕES E DESENVOLVIMENTOS FUTUROS}

Os resultados obtidos revelaram as potencialidades da visão computacional quanto a uma descrição objectiva, sistemática e quantificada das dinâmicas de mobilidade associadas aos cenários de uso estudados. Foi possível descrever de modo quantificado os comportamentos de navegação nos átrios através da discriminação de índices directamente associados aos padrões de mobilidade computacionalmente deduzidos. Tais índices quantificaram a descrição dos movimentos dos utilizadores demonstrando o seu potencial de aplicação muito além da limitada contagem de indivíduos, e a descrição subjectiva dos seus trajectos no espaço, expressa nos procedimentos de observação standard consagrados no âmbito da Sintaxe Espacial. Os padrões de mobilidade permitiram conferir visibilidade à configuração dos movimentos nos espaços observados.

O registo sistemático e continuado das regularidades ou invariâncias dos fenómenos de mobilidade, e o seu tratamento estatístico, permitem evidenciar a configuração da ocupação e do movimento (i.e., a sua forma ou modo como este se organiza no espaço) e assim compreender a estrutura que a regula (i.e., o conjunto de eixos de ocupação/movimento predominantes que determinam a forma da ocupação e do movimento). Esta representação e 


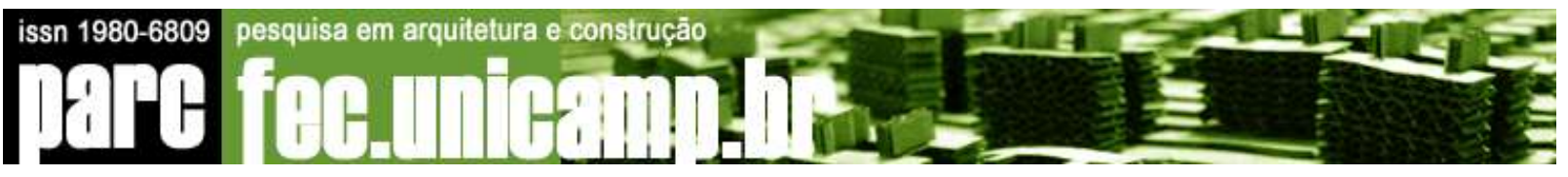

descrição da configuração do movimento constitui um passo essencial para a análise de nexos com a configuração do espaço.

$\mathrm{Na}$ visão computacional da mobilidade os registos caracterizam-se pela sua intermutabilidade: os resultados gráficos são gerados a partir dos resultados estatísticos; na ausência dos primeiros é possível a sua reconstituição a partir dos segundos. Uma das consequências dessa capacidade é a associação directa entre espaço e índices de mobilidade na medida em que os mapas representam a distribuição espacial dos índices. Os mapas de ocupação e os mapas de fluxos constituem sínteses da relação entre espaço e movimento, ou dito de outro modo, os mapas constituem descrições do espaço através dos movimentos que o percorrem. Os mapas estatísticos, obtidos pela visão computacional, resultam em efectivas representações de síntese das relações espaço-uso, matematicamente expressas por meios gráficos, onde os factores não podem ser separados.

Por este motivo os mapas de ocupação permitem estabelecer conexões directas com os grafos de visibilidade permitindo (de modo equivalente a estes) uma interpretação em termos gráficos e outra em termos quantitativos da configuração do movimento. A sobreposição dos dois registos (mapas e grafos) permite estabelecer, para cada ponto do espaço observado, a correlação entre o valor da propriedade configuracional do espaço e o valor do índice de mobilidade.

Os mapas de ocupação caracterizam-se, ainda, pela valorização de comportamentos de grupo e dissociação do movimento individual (quando se contabilizam as pausas distinção dos sub-índices MOVING e STOPPED - não se considera a sequência de movimento a que pertencem). São essencialmente vocacionados para a identificação de regularidades nas dinâmicas de mobilidade. O tratamento estatístico desses dados permite revelar os vectores de movimento estruturantes dessas dinâmicas cuja compreensão é essencial ao estudo das relações espaço-uso.

Por este motivo os mapas de ocupação permitem, também, analisar nexos entre a estrutura das dinâmicas de mobilidade e o mapa axial. Mais uma vez, é possível determinar os valores dos índices de ocupação associados aos eixos de mobilidade e correlacioná-los 
com os valores de integração, por exemplo, dos eixos de acessibilidade espacial (física e visual).

Complementarmente, os mapas de fluxos permitem detalhar a análise do movimento pois correspondem às descrições na íntegra dos comportamentos de navegação individuais dos utilizadores. A possibilidade de identificar cada trajectória no espaço constitui a plataforma para fundamentar uma futura taxonomia do movimento e, também, uma ponte para aprofundar estudos na área da cognição espacial ${ }^{14}$. Cada registo de movimento corresponde à expressão, no espaço, do indivíduo que o produziu e do modo como este teceu relações com esse contexto. Comportamentos diversos ou desviantes da norma definida pelo grupo emergem dos padrões de fluxos.

A evolução deste método decorrerá da experiência adquirida no desenvolvimento da sua versão experimental. A prática revelou a necessidade de desenvolver procedimentos analíticos informaticamente apoiados. O acervo de resultados obtidos não se coaduna com a sua análise sustentada nos atrás referidos processos manuais. A análise e a interpretação dos resultados beneficiariam do desenvolvimento de uma ferramenta de apoio que permitisse automatizar procedimentos estabelecendo, entre outras funcionalidades, as conjugações desejadas entre mapas, entre mapas e imagens de referência, e calculasse automaticamente os índices para cada ponto ou zona do mapa pretendida (FIG. 17). Beneficiaria, igualmente, com a possibilidade de dissociação e de recombinação dos mapas de fluxos de acordo com determinados critérios de análise (associados ao número de pausas e geometria das trajectórias, por exemplo). Será desejável tais funcionalidades abarcarem, ainda, a possibilidade de articulação com as representações sintácticas e a produção automática de elementos de síntese como gráficos e diagramas de dispersão, por exemplo.

Sendo a aquisição de imagens fulcral a qualquer método de análise da mobilidade entende-se ser importante aligeirar os procedimentos que Ihe sejam relacionáveis. Maior complexidade de meios equivale a mais informação mas, também, a mais problemas técnicos. Daí a pertinência em minimizar essa complexidade e aumentar a operacionalidade recorrendo a outros tipos de equipamentos, nomeadamente, câmaras portáteis. 

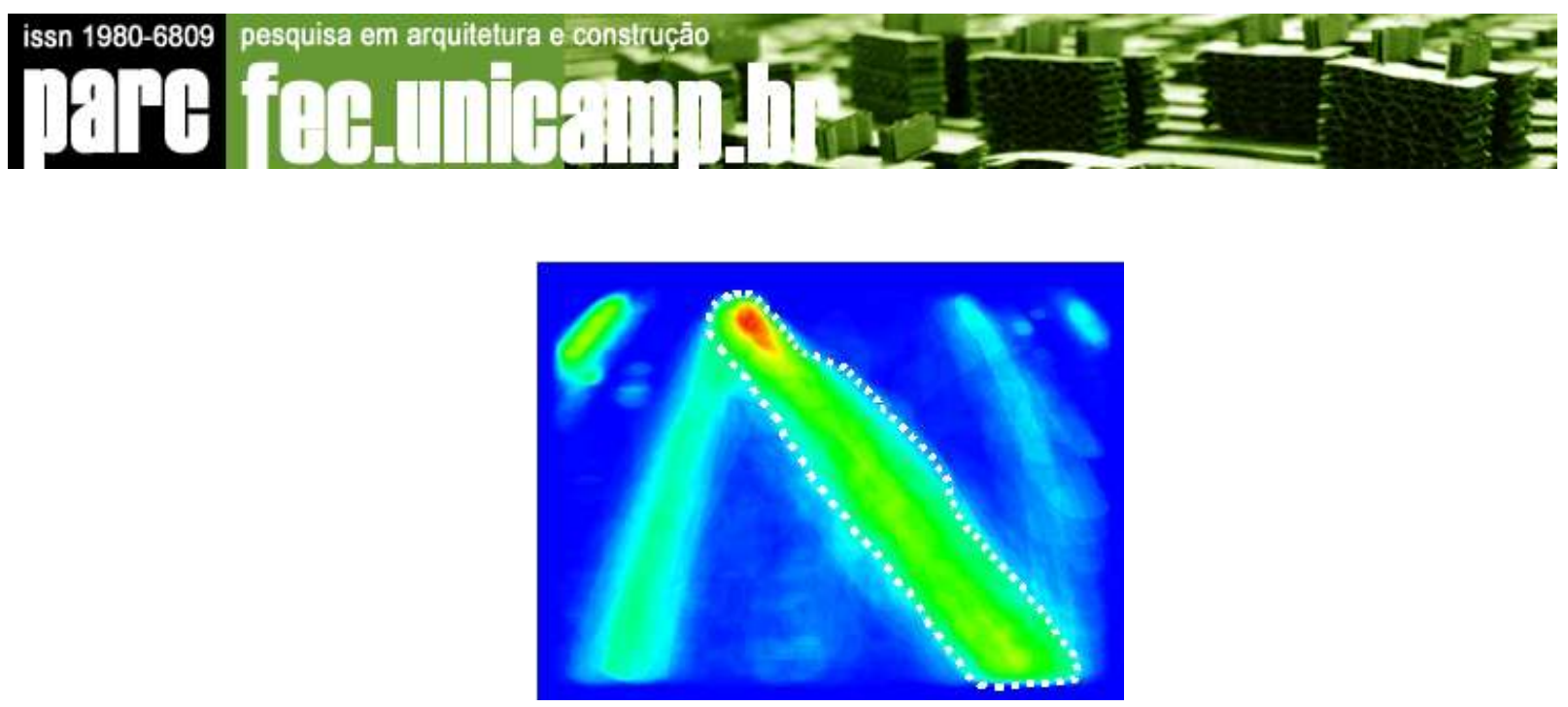

FIGURA 17: Desenvolvimento de um software de apoio à análise dos resultados permitindo, por exemplo, calcular o valor do índice associado a um eixo de ocupação.

A relevância da eficiência destes procedimentos de aquisição de dados reside na possibilidade da sua universalização e, consequentemente, na disponibilização de um banco partilhável por investigadores. Tal banco, ao permitir a reunião da maior diversidade possível de cenários de uso, e respectivos padrões de mobilidade, constituirá um significativo contributo para o estudo das relações entre a morfologia espacial e a morfologia do movimento. A detecção de regularidades entre tipologias espaciais e tipologias de movimento permitirá a fundamentação de critérios de projecto visando a eficácia da vertente funcional dos espaços alicerçada na previsão das dinâmicas de movimento e ocupação passíveis de serem geradas pelos espaços projectados. Os programas de projectos de arquitectura, menos normativos e mais prescritivos, deixariam de ser especificados exclusivamente com base na identificação de áreas, requisitos funcionais e requisitos técnicos. Seriam, igualmente e adequadamente, informados pelas estruturas configuracionais de movimento e interacção que deveriam promover.

A visão computacional da mobilidade nos átrios do DECivil revelou-se uma ferramenta analítica de natureza evolutiva particularmente adequada ao estudo das relações entre o espaço e os seus usos. O constante aumento das capacidades de processamento dos sistemas informáticos e respectivos hardwares permite sustentar, de modo credível, essa natureza evolutiva do método. A visão computacional da mobilidade é a visão pelos olhos da matemática e da estatística sustentada pela capacidade interpretativa da microinformática. 


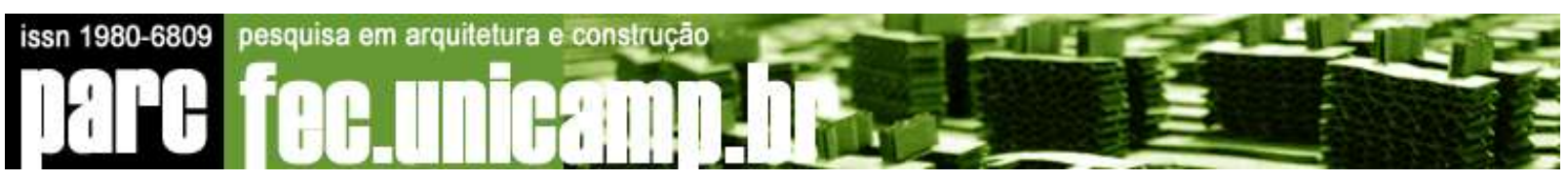

\section{Referências}

HILLIER, B.; HANSON, J. The social logic of space. Cambridge: Cambridge University Press, 1984.

HILLIER, B.; PENN, A. Visible Colleges: Structure and Randomness in Place of Discovery. Science in Context 4, 1, 1991, p. 23-49. Disponível em: < http://eprints.ucl.ac.uk/1007/1/hillier-penn-1991a.pdf> Acesso em: dez. 2007.

HILLIER, B. (1996). Space is the machine. Cambridge: Press Syndicate of the University of Cambridge, 1996.

Disponível

em: <http://eprints.ucl.ac.uk/archive/00003881/01/SITM.pdf> Acesso em: out. 2006.

HEITOR, T.; TOMÉ, A. Can mobility flow analysis improve informal learning processes in traditional education establishments? In: 7th Space Syntax International Symposium, 2009, Estocolmo, Suécia. Proceedings... Estocolmo, TRITA-ARKForskningspublikation, 2009, p. 040:1-040:13.

LAHR, C. Manual de Filosofia. Resumido e adaptado por G.P. a partir da versão original Cours de Philosophie, 1900. Porto: Livraria Apostolado da Imprensa, 1948.

TURNER, A.; PENN, A. Encoding natural movement as an agent-based system: an investigation into human pedestrian behavior in the built environment. Environment and Planning B: Planning and Design, vol. 29, 2002, p. 473-490.

VAUGHAN, L. Space Syntax - Observation Procedures Manual. Versão original de Tad Grajewski, 1992. Londres: Space Syntax Laboratory, Bartlett School of Architecture and Planning University College, 2001 [mensagem pessoal]. Mensagem recebida por <anatome@civil.ist.utl.pt> em 25 mar. 2008. 


\section{Notas}

1 Pavilhão do Departamento de Engenharia Civil, Arquitectura e Georecursos.

2 Instituto Superior Técnico.

3 Modelo sintáctico que representa as relações de contenção espacial e de contiguidade espacial entre espaços constituintes dum sistema. Pressupõe a fragmentação do sistema espacial no menor conjunto de espaços convexos de maior área. Espaço convexo: aquele em que qualquer linha unindo dois pontos está inteiramente nele contida. Por conseguinte, todos os pontos desse espaço são directamente acessíveis e visíveis a partir de qualquer localização interna arbitrariamente definida.

4 Mestrado Integrado em Arquitectura.

5 Inesc Inovação, Instituto de Novas Tecnologias (http://www.inov.pt/).

6 Frames Per Second.

7 Red, Green and Blue.

8 Internet Protocol.

9 Power over Ethernet.

10 Concepção: INOV - Inesc Inovação, Instituto de Novas Tecnologias (http://www.inov.pt/).

11 Modelo sintáctico que representa a distribuição das propriedades configuracionais do espaço passível de ocupação segundo um continuum. O grafo resulta da divisão do sistema espacial segundo uma grelha (cuja malha é definida de acordo com a finura da análise pretendida) e união de cada ponto $\mathrm{P}$ (correspondente a cada quadrícula ou célula) dessa malha a todos os outros pontos do sistema visíveis a partir de $\mathrm{P}$.

12 Propriedade configuracional do espaço. No grafo de um sistema espacial, corresponde à distância média de cada vértice a todos os outros vértices do sistema. A integração de um vértice será tanto mais elevada quanto menor for a sua distância média. A integração visual corresponde à acessibilidade (ou permeabilidade) do espaço em termos visuais. Grafo é o objecto básico da teoria dos grafos (matemática). Matematicamente corresponde a uma estrutura $G(V, A)$ onde $V$ é um conjunto não vazio de objectos designados por vértices e $A$ é um conjunto de pares não ordenados de V, designados por arestas. Graficamente a sua representação corresponde a um conjunto de pontos (os vértices) ligados por linhas rectas (as arestas).

13 A configuração axial de um sistema espacial é descrita pelo mapa axial. O mapa axial representa as relações de acessibilidade visual e física num sistema espacial. Corresponde ao menor conjunto de linhas axiais de maior comprimento que, num sistema espacial, cobrem todo o conjunto de espaços convexos e suas conexões.

14 O conceito de "espaço hodológico" (http://www.sbdg.org.br/web/artigos det.php?id=450 e http://www.vitruvius.com.br/revistas/read/arquitextos/10.112/24) constituirá um contributo para questionar e esclarecer as dimensões perceptivas subjacentes ao movimento humano no espaço construído.

\section{Agradecimentos}

Este trabalho é parte da actividade de pesquisa realizada no ICIST, Instituto de Engenharia de Estruturas, Território e Construção e foi apoiado pela Fundação da Ciência e Tecnologia através do financiamento das unidades de investigação. 